\title{
Multivalent glibenclamide to generate islet specific imaging probes
}

Andrej Babic ${ }^{\dagger f}$, Smaragda Lamprianou ${ }^{\ddagger £}$, Laurent Vinet $^{\ddagger}$, Nathalie Stransky-Heilkron ${ }^{\dagger}$, Celine Xayaphoummine $^{\dagger}$, Marino A. Campo ${ }^{\dagger}$, Heiner Glombik ${ }^{\S}$, Anke Schulte ${ }^{\S}$, Hans-Paul Juretschke ${ }^{\S}$, Xavier Montet ${ }^{\sharp}$, Paolo Meda ${ }^{\ddagger}$, and Norbert Lange ${ }^{+{ }^{*}}$

'School of Pharmaceutical Sciences Geneva-Lausanne, University of Geneva, University of Lausanne, Geneva, Switzerland

${ }^{\ddagger}$ Department of Cell Physiology and Metabolism, University of Geneva Medical School, Geneva, Switzerland

\# Department of Radiology, Geneva University Hospital, Geneva, Switzerland ${ }^{s}$ Sanofi Germany, Industriepark Höchst, Frankfurt, Germany

${ }^{£}$ These authors contributed equally to this work

*Corresponding Author: Norbert Lange

School of Pharmaceutical Sciences

University of Geneva, University of Lausanne

30, Quai Ernest Ansermet

1211 Geneva

Switzerland

e-mail: norbert.lange@unige.ch

Tel: +41 223793335

Fax: +41 223796567

(C) 2015. This manuscript version is made available under the Elsevier user license 
ABSTRACT: The monitoring of diabetes mellitus, as it develops and becomes clinically evident, remains a major challenge for diagnostic imaging in clinical practice. Here we present a novel approach to beta-cell imaging by targeting the sulphonylurea receptor subtype 1 (SUR1), using multivalent derivatives of the anti-diabetic drug glibenclamide.

Since glibenclamide has a high affinity for SUR1 but does not contain a suitable functional group to be linked to an imaging probe, we have synthesized 11 glibenclamide derivatives and evaluated their affinity to SUR1 in MIN6 cells. The most promising compound has been used to obtain multivalent glibenclamide-polyamidoamine (PAMAM) derivatives, containing up to 15 sulphonylurea moieties per dendrimer. The remaining functional groups on the dendrimers can consecutively be used for labeling with reporter groups for different imaging modalities, thus allowing for multifunctional imaging, and for the modification of pharmacokinetic properties. We synthesized fluorochrome-labeled multivalent probes, that demonstrate in cellular assays affinities to SUR1 in the nanomolar range, superior to native glibenclamide. The probes specifically label MIN6 cells, but not HeLa or PANC-1 cells which do not express SUR1. A very low cytotoxicity of the multivalent probes is demonstrated by the persistent release of insulin from MIN6 cells exposed to high glucose concentrations. Furthermore, the probes display positive labeling of beta-cells of primary mouse and human islet-cells ex vivo and of islets of Langerhans in vivo. The data document that multivalent probes based on glibenclamide derivatives provide a suitable platform for further developments of cell-specific probes, and can be adapted for multiple imaging modalities, including those that are now used in the clinics.

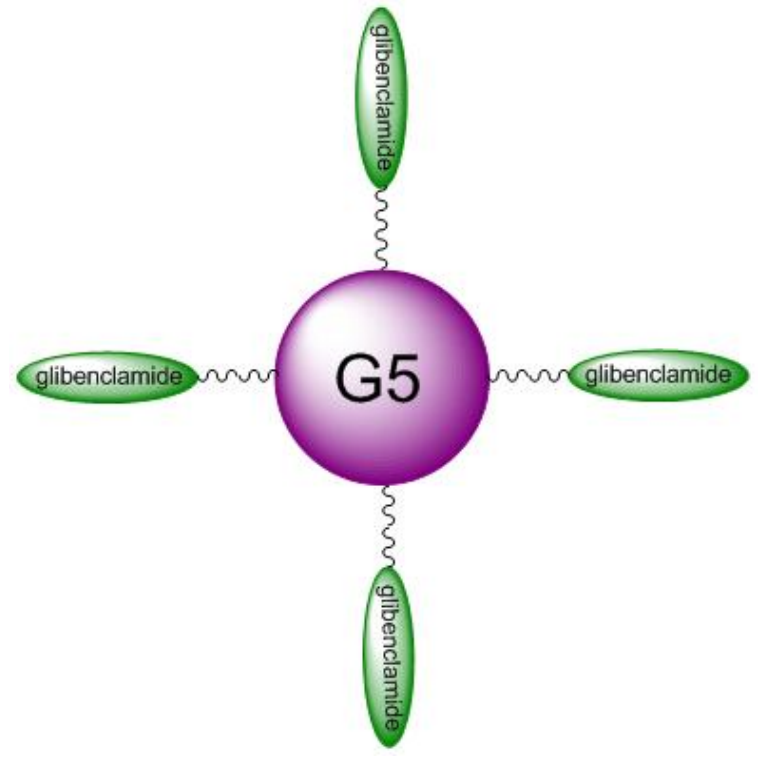

KEYWORDS: multivalency, imaging, beta-cells, diabetes, sulphonylureas, dendrimers 


\section{INTRODUCTION}

Diabetes affects over 380 million people today with at least 1.5 million deaths per year and it is expected to increase by $30-50 \%$ in the next 20 years ${ }^{(1)}$. The disease occurs following an impairment of the mass and/or function of the insulin-producing pancreatic beta-cells ${ }^{(2-4)}$. The natural history of the disease and the underlying causes are still a matter of debate ${ }^{(5,6)}$, and the molecular and cellular mechanisms of the disease are not fully understood. This unsatisfactory situation is largely due to the lack of non-invasive techniques that would allow to monitor the onset and the progression of diabetes, specifically by imaging. These techniques would also enable us to evaluate the outcome of candidate therapeutic approaches, aiming at promoting the regeneration of beta-cells or fostering insulin production and secretion. Forthcoming beta-cell and transplantation treatments ${ }^{(7,8)}$ will also heavily rely on the accurate monitoring of the newly developing beta-cell mass.

There are several anatomical and technical features that restrict therapeutic monitoring of betacells. First, there is the minute size of beta-cells-harboring islets, which measure $30-600 \mu \mathrm{m}$ in diameter, and are scattered throughout the pancreas. In adults, these islets constitute no more than $2 \%$ of the pancreatic mass, and contain other types of hormone-producing cells such as alpha, delta, epsilon and pancreatic polypeptide producing (PP) cells ${ }^{(2,3)}$. Second, the pancreas is located deep inside the abdomen, where it is closely surrounded by other major organs. Third, the acquisition of images is complicated by circulatory, respiratory and bowel movements, which limit the choice of appropriate imaging modalities. A number of these limitations can be addressed by the development of beta-cell-specific probes.

To this end, substantial effort has been put into the identification of beta-cell-specific molecular targets and the design of corresponding reporters ${ }^{(9-15)}$. However, most of these probes lack sensitivity ${ }^{(16)}$ and specificity for clinical use ${ }^{(17-21)}$. Thus, alternative approaches that target epitopes of beta-cells ${ }^{(22-25)}$ using low molecular weight compounds already in clinical use should be considered.

Besides glucagon-like peptide-1 (GLP-1) receptor agonists ${ }^{(18,26-30)}$, the sulphonylureas are such a class of compounds. They interact with the sulphonylurea receptors 1 (SUR1), which together with $\mathrm{K}_{\mathrm{IR}} 6.2$ form the ATP sensitive $\mathrm{K}^{+}$-channels that are largely expressed on the secretory granules and the membrane of beta-cells, and to a lesser degree of other islet cells ${ }^{(31-36)}$. Among these ligands glibenclamide is known for its high affinity to SUR1 and has been marketed for the treatment of type 2 diabetes since the 1960s ${ }^{\left({ }^{37}\right)}$. Glibenclamide and other sulphonylureas have been previously tested for beta-cell imaging with limited success. These studies revealed that the glibenclamide probes provide limited and short-lived beta-cell labeling due to their poor internalization by the target cells, high-plasma protein binding, due to their high lipophilicity, and in most cases non-specific labeling of nearby cells and organs. ${ }^{(16,38-41)}$.

Here, we propose an alternative approach towards addressing these issues, by targeting beta-cells with multivalent glibenclamide probes. Matching the receptor density at the cell surface with multivalent ligands can dramatically improve probe specificity ${ }^{(42,43)}$. This should favor binding 
to receptors which are more expressed in beta-cells than in other cell types ${ }^{(44)}$. For this purpose we first set up a novel in vitro test allowing for the assessment of the binding affinity of glibenclamide, and derived multivalent probes to be tested in living cells. We then analyzed the specificity of selected probes in cells lacking SUR1 expression. We subsequently tested the binding of the most promising probe in islets isolated from the pancreas of adult mice and of multi-organ donors, and after injection in mice.

\section{MATERIALS AND METHODS}

General Information and Methods. All chemicals were purchased from Sigma-Aldrich and Acros and used as received. All reactions were performed under inert argon conditions unless otherwise noted. Silica-Flash P60 silica gel $(40-63 \mu \mathrm{m})$ from SiliCycle was used for flash chromatography. Analytical thin layer chromatography was performed using TLC Silica gel 60

$\mathrm{F}_{254}$ alumina plates. ${ }^{1} \mathrm{H},{ }^{13} \mathrm{C}$, APT, COSY, HMBC and HSQC NMR experiments were performed at $298 \mathrm{~K}$ on a Varian Anova 300 and $500 \mathrm{MHz}$ spectrometers at the School of Pharmaceutical Sciences and Bruker Avance 300 and Bruker Cryo-Avance III $500 \mathrm{MHz}$ spectrometers at the Chemistry NMR facility at the University of Geneva, Switzerland or at Sanofi, Germany. All chemical shifts are reported in the standard notation of parts per million using the peak of residual proton and carbon signals of the solvent as internal references. NMR peaks are referred to as singlet (s), doublet (d), doublet of doublets (dd), triplet (t), broad singlet (br s), or multiplet $(\mathrm{m})$. Coupling constants $(J)$ are reported in Hertz. Low-resolution mass spectroscopy using electrospray ionization (ESI) were performed on API 150EX from AB/MDS Sciex and MALDITOF analysis were performed on Axima $\mathrm{CFR}^{+}$from Shimadzu using CHCA as matrix. Highresolution mass spectroscopy measurements were performed on QSTAR pulsar from AB/MDS Sciex. HPLC and GPC analyses were performed on Merck Hitachi LaChrom 7000 series system equipped with diode-array and fluorescence detectors. HPLC analyses were performed using Macherey Nagel C18 $3 \mu \mathrm{m}$ Gravity $125 \times 4.0 \mathrm{~mm}$ column and GPC analyses were performed using Phenomenex BioSep SEC-S2000 300×4.6 mm column. Preparative RP-HPLC was performed on Water delta 600 HPLC system equipped with Water 2487 dual wavelength detector and Macherey Nagel Nucleodur C18-Htec $5 \mu \mathrm{m}$ 250×21 mm semi-preparative column or Waters Symmetry C4 $5 \mu \mathrm{m}, 19 \times 150 \mathrm{~mm}$ semi-preparative column. Chemical structures were drawn and named according IUPAC nomenclature using ChemBioDraw version 14.0.0.117 software package. NMR spectra were processed with Mnova version 8.0.2 software package. MALDI spectra were processed using Shimadzu Biotech LaunchPad 2.8 software. Statistics and data from biological experiments were treated and analyzed with GraphPad Prism 6.0.1. P values $<0.05$ were considered as statistically significant. Compounds 5, 6, 7, 8, 9, 10, 11 were synthesized and provided by Sanofi, Germany as in-kind contribution. 


\section{Chemistry}

(See synthesis schemes S-1 and S-2 in supplementary content)

4-amino-5-chloro- $N$-(4-(N-(cyclohexylcarbamoyl)sulfamoyl)phenethyl)-2-methoxybenzamide (2)

Tert-butyl 4-(N-cyclohexylcarbamoyl)sulfamoyl)phenethylcarbamate (640 $\mathrm{mg}, 1.50 \mathrm{mmol})$ was dissolved in dichloromethane $(20.0 \mathrm{~mL})$ and trifluoroacetic acid $(2.00 \mathrm{~mL})$ was added. The reaction was followed by TLC and judged complete after $1 \mathrm{~h}$ at ambient temperature. The solvents were evaporated under reduced pressure. The product 4-(2-aminoethyl)-N(cyclohexylcarbamoyl)- benzenesulfonamide was used without purification in the next step. 4amino-5-chloro-2-methoxybenzoic acid $(300 \mathrm{mg}, 1.50 \mathrm{mmol})$ and carbonyldiimidazole $(0.265 \mathrm{~g}$, $(1.63 \mathrm{mmol})$ were dissolved in DMF $(5.00 \mathrm{~mL})$ and stirred at ambient temperature for $1 \mathrm{~h}$. At this point, 4-(2-aminoethyl)-N-(cyclohexylcarbamoyl) benzenesulfonamide (0.660 g, $1.50 \mathrm{mmol})$ and diisopropylethylamine $(0.384 \mathrm{~g}, 3.00 \mathrm{mmol})$ were added and the reaction mixture kept stirring. After $12 \mathrm{~h}$ the solvents were evaporated under reduced pressure and the crude product purified by flash chromatography (DCM/MeOH gradient) giving colorless solid (150 mg, $0.300 \mathrm{mmol}$, 29.4\% yield). ${ }^{1} \mathrm{H}$ NMR (300 MHz, DMSO- $\left.d 6\right) \delta 10.32(\mathrm{~s}, 1 \mathrm{H}), 7.90(\mathrm{t}, J=5.7 \mathrm{~Hz}, 1 \mathrm{H}), 7.83(\mathrm{~d}$, $J=8.4 \mathrm{~Hz}, 2 \mathrm{H}), 7.69(\mathrm{~s}, 1 \mathrm{H}), 7.47(\mathrm{~d}, J=8.4 \mathrm{~Hz}, 2 \mathrm{H}), 6.44(\mathrm{~s}, 1 \mathrm{H}), 6.32(\mathrm{~d}, J=6.3 \mathrm{~Hz}, 2 \mathrm{H})$, $5.95(\mathrm{~s}, 1 \mathrm{H}), 3.72(\mathrm{~s}, 3 \mathrm{H}), 3.53(\mathrm{~m}, 2 \mathrm{H}), 3.27-3.25(\mathrm{~m}, 1 \mathrm{H}), 2.91(\mathrm{t}, J=6.9 \mathrm{~Hz}, 2 \mathrm{H}), 1.66-1.50$ $(\mathrm{m}, 6 \mathrm{H}), 1.15-1.03(\mathrm{~m}, 4 \mathrm{H}) .{ }^{13} \mathrm{C}$ NMR (75 MHz, DMSO-d6): 164.28, 158.04, 151.17, 149.21, 146.09, 138.86, 132.21, 129.94, 128.06, 110.95, 109.61, 98.18, 56.43, 48.78, 35.67, 32.98, 25.69, 24.88. (LRMS, ESI): $\mathrm{m} / \mathrm{z}$ calculated for [M-H] 507.16, 509.16, found 507.5, 509.5. (HRMS, ESI): $\mathrm{m} / \mathrm{z}$ calculated for $[\mathrm{M}+\mathrm{H}]^{+} 509.1620$, found 509.1617 .

Trifluoroacetic acid salt of 4-(3-(4-aminobutyl)ureido)-5-chloro-N-(4-(N-(cyclohexyl carbamoyl)sulfamoyl) phenethyl)-2-methoxybenzamide (3)

Compound $2(50.0 \mathrm{mg}, 98.2 \mu \mathrm{mol})$ was dissolved in dry THF $(10.0 \mathrm{~mL})$. Dry pyridine $(27.0 \mathrm{mg}$, $342 \mu \mathrm{mol})$ and diphosgene $(55.0 \mathrm{mg}, 555 \mu \mathrm{mol})$ were added slowly to the reaction mixture at room temperature. After stirring for $1.5 \mathrm{~h}$, butane-1,4-diamine $(550 \mathrm{mg}, 6.25 \mu \mathrm{mol})$ dissolved in dry THF $(10.0 \mathrm{~mL})$ was added and the reaction mixture stirred for another $1 \mathrm{~h}$. The reaction was quenched by the addition of water $(3.00 \mathrm{~mL})$ and THF evaporated under reduced pressure. Brine $(15.0 \mathrm{~mL})$ was added and the colorless solid was centrifuged off. The crude product was purified by reverse phase HPLC using water/acetonitrile (0.1\% TFA) 65/35 isocratic elution on Waters Symmetry C4 $5 \mu \mathrm{m}, 19 \times 150 \mathrm{~mm}$ column. Colorless solid $(24.0 \mathrm{mg}, 32.6 \mu \mathrm{mol}, 33.2 \%$ yield) was obtained. ${ }^{1} \mathrm{H}$ NMR $(300 \mathrm{MHz}, \mathrm{DMSO}-d 6) \delta 10.42(\mathrm{~s}, 1 \mathrm{H}), 8.23(\mathrm{~s}, 1 \mathrm{H}), 8.18(\mathrm{~s}, 1 \mathrm{H}), 8.10(\mathrm{t}, J=$ $5.7 \mathrm{~Hz}, 1 \mathrm{H}), 7.84(\mathrm{~d}, J=8.1 \mathrm{~Hz}, 2 \mathrm{H}), 7.77(\mathrm{~s}, 1 \mathrm{H}), 7.70(\mathrm{br} \mathrm{s}, 3 \mathrm{H}) 7.48(\mathrm{~d}, J=8.1 \mathrm{~Hz}, 2 \mathrm{H}), 7.35$ $(\mathrm{t}, J=5.4 \mathrm{~Hz}, 1 \mathrm{H}), 6.45(\mathrm{~d}, J=8.1 \mathrm{~Hz} 1 \mathrm{H}), 3.76(\mathrm{~s}, 3 \mathrm{H}), 3.57-3.50(\mathrm{~m}, 4 \mathrm{H}), 3.27-3.25(\mathrm{~m}, 1 \mathrm{H})$, $3.13(\mathrm{~m}, 2 \mathrm{H}), 2.93(\mathrm{t}, J=6.9 \mathrm{~Hz}, 2 \mathrm{H}), 2.81(\mathrm{~m}, 2 \mathrm{H}), 1.66-1.50(\mathrm{~m}, 10 \mathrm{H}), 1.15-1.03(\mathrm{~m}, 4 \mathrm{H}) .{ }^{13} \mathrm{C}$ NMR (75 MHz, DMSO-d6): $\delta$ 163.82, 157.04, 155.24, 151.17, 145.95, 140.89, 138.89, 131.41, $129.95,128.07,116.20,112.40,103.27,56.60,56.55,48.78,39.15,35.50,32.99,27.24,25.68$, 
25.27, 24.90. (LRMS, ESI): $\mathrm{m} / \mathrm{z}$ calculated for $[\mathrm{M}+\mathrm{H}]^{+}$623.24, 625.24, found 623.3, 625.3. (HRMS, ESI): $\mathrm{m} / \mathrm{z}$ calculated for $[\mathrm{M}+\mathrm{H}]^{+}$623.2413, found 623.2406.

5-(3-(2-chloro-4-((4-(N-(cyclohexylcarbamoyl)sulfamoyl)phenethyl)carbamoyl)-5-methoxy phenyl)ureido)pentanoic acid (4)

Compound 2 (50 mg, $0.10 \mathrm{mmol}$ ) and diisopropylethylamine (70 $\mu \mathrm{L}, 0.40 \mathrm{mmol})$ were dissolved in dry THF and cooled to $0^{\circ} \mathrm{C}$. Diphosgene $(79 \mathrm{mg}, 0.40 \mathrm{mmol})$ was added drop wise to the cooled solution. The reaction was heated at $50{ }^{\circ} \mathrm{C}$ for $2 \mathrm{~h}$ and then the solvents evaporated under reduced pressure. The crude product was washed with hexane $(2 \times 15 \mathrm{~mL})$ and dried under high vacuum. The crude product was redissolved in dry THF $(3.00 \mathrm{~mL})$ before 5 -aminopentanoic acid $(150 \mathrm{mg}, 1.28 \mathrm{mmol})$ and DBU $(0.460 \mathrm{~g}, 3.00 \mathrm{mmol})$ dissolved in dry DMSO $(4.00 \mathrm{~mL})$ were added. After $1 \mathrm{~h}$, THF was evaporated and a solution containing brine $(24.0 \mathrm{~mL})$, concentrated $\mathrm{HCl}(1.60 \mathrm{~mL})$ and water $(2.40 \mathrm{~mL})$ was added. The precipitate was collected by centrifugation, washed with water $(5.00 \mathrm{~mL})$, and dried under a stream of argon. Crude product was purified by RP-HPLC using water/acetonitrile $(0.1 \%$ TFA) gradient on Waters Symmetry C4 $5 \mu \mathrm{m}, 19 \times 150$ $\mathrm{mm}$ column. The fractions containing the product were pooled and freeze-dried to obtain a colorless fluffy solid (25.0 mg, $38.3 \mu \mathrm{mol}, 38.3 \%$ yield). ${ }^{1} \mathrm{H}$ NMR (300 MHz, DMSO-d6) $\delta$ $10.39(\mathrm{~s}, 1 \mathrm{H}), 8.20(\mathrm{~d}, J=8.1 \mathrm{~Hz}, 2 \mathrm{H}), 8.10(\mathrm{t}, J=5.7 \mathrm{~Hz}, 1 \mathrm{H}), 7.84(\mathrm{~d}, J=8.1 \mathrm{~Hz}, 2 \mathrm{H}), 7.77$ (s, $1 \mathrm{H}), 7.48(\mathrm{~d}, J=8.4 \mathrm{~Hz}, 2 \mathrm{H}), 7.28(\mathrm{t}, J=5.1 \mathrm{~Hz}, 1 \mathrm{H}), 6.35(\mathrm{~d}, J=7.8 \mathrm{~Hz} 1 \mathrm{H}), 3.76(\mathrm{~s}, 3 \mathrm{H})$, $3.59-3.52(\mathrm{~m}, 2 \mathrm{H}), 3.28-3.26(\mathrm{~m}, 1 \mathrm{H}), 3.15-3.11(\mathrm{~m}, 2 \mathrm{H}), 2.93(\mathrm{t}, J=6.9 \mathrm{~Hz}, 2 \mathrm{H}), 2.25(\mathrm{t}, J=$ $6.9 \mathrm{~Hz}, 2 \mathrm{H}), 1.66-1.45(\mathrm{~m}, 9 \mathrm{H}), 1.23-1.04(\mathrm{~m}, 5 \mathrm{H}) .{ }^{13} \mathrm{C}$ NMR $(75 \mathrm{MHz}, \mathrm{DMSO}-d 6): \delta 175.12$, 163.85, 157.06, 155.14, 151.13, 145.99, 140.98, 138.85, 131.37, 129.97, 128.08, 116.10, 112.36, 103.26, 56.62, 48.79, 35.49, 33.99, 32.98, 29.61, 25.68, 24.89, 22.67. (LRMS, ESI): m/z calculated for $[\mathrm{M}-\mathrm{H}]^{-} 650.21,652.21$, found $650.7,652.7$; calculated for $[\mathrm{M}+\mathrm{H}]^{+} 652.21,654.21$, found $652.3,654.3$. (HRMS, ESI): $\mathrm{m} / \mathrm{z}$ calculated for $[\mathrm{M}+\mathrm{H}]^{+} 652.2202$, found 652.2222 .

tert-butyl-(2-(2-(2-(4-chloro-2-((4-(N-(cyclohexylcarbamoyl) sulfamoyl)phenethyl) carbamoyl)phenoxy)ethoxy)ethoxy)ethyl)carbamate (10)

tert-Butyl N-[2-[2-(2-iodoethoxy)ethoxy]ethyl]carbamate (13) 2-[2-[2-(tert-butoxycarbonylamino)ethoxy]ethoxy]ethyl methanesulfonate $(3.25 \mathrm{~g}, 10.0 \mathrm{mmol})$ and sodium iodide $(5.25 \mathrm{~g}, 35.0 \mathrm{mmol})$ were dissolved in acetonitrile $(32.5 \mathrm{~mL})$. The yellow to orange solution was stirred for $1.5 \mathrm{~h}$ under reflux, resulting in a yellow suspension. After cooling, the solvent was removed under reduced pressure, the residue was dissolved in ethylacetate and extracted with water. The product obtained from the organic layer after drying over sodium sulfate and solvent removal was deemed sufficiently pure by ${ }^{1} \mathrm{H}$ NMR and was used in the next reaction step without further purification. ${ }^{1} \mathrm{H}$ NMR (400 MHz, DMSO- d6): $\delta 3.66(\mathrm{t}, 2 \mathrm{H}), 3.53(\mathrm{~m}, 4 \mathrm{H}), 3.39$

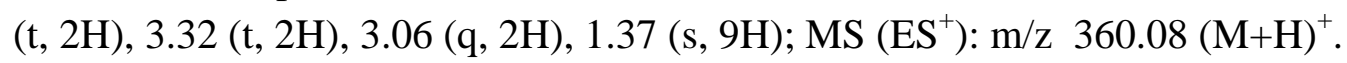

Methyl 2-[2-[2-[2-(tert-butoxycarbonylamino)ethoxy]ethoxy]ethoxy]-5-chloro-benzoate 
methyl 5-chloro-2-hydroxy-benzoate $(1.90 \mathrm{~g}, 10.2 \mathrm{mmol})$ and sodium hydride $(60 \%$ suspension in mineral oil) $(0.46 \mathrm{~g}, 11.5 \mathrm{mmol})$ in dry DMF $(24.0 \mathrm{~mL})$ were stirred under argon at ambient temperature for $20 \mathrm{~min}$. After a yellow suspension was formed, a solution of tert-butyl N-[2-[2(2-iodoethoxy)ethoxy]ethyl]carbamate $(3.42 \mathrm{~g}, 9.53 \mathrm{mmol})$ in dry DMF $(12.0 \mathrm{~mL})$ was added dropwise, and the mixture stirred for $2 \mathrm{~h}$ at $70{ }^{\circ} \mathrm{C}$ and $1 \mathrm{~h}$ at $85{ }^{\circ} \mathrm{C}$. After cooling and standing over night, methanol $(2.00 \mathrm{~mL})$ was added and solvents were removed under reduced pressure. The residue was dissolved in ethylacetate, extracted with water, and after drying the organic layer, removal of the solvent and flash chromatography using heptane/ethylacetate gradient, the colorless product was obtained (3.07 g, $7.34 \mathrm{mmol}, 77.0 \%$ yield). ${ }^{1} \mathrm{H}$ NMR (400 MHz, DMSO$d 6): \delta 7.62(\mathrm{~d}, 1 \mathrm{H}), 7.57(\mathrm{dd}, 1 \mathrm{H}), 7.20(\mathrm{~d}, 1 \mathrm{H}), 6.71(\mathrm{br} \mathrm{t}, 1 \mathrm{H}), 4.15(\mathrm{t}, 2 \mathrm{H}), 3.79(\mathrm{~s}, 3 \mathrm{H}), 3.73(\mathrm{t}$, $2 \mathrm{H}), 3.59(\mathrm{~m}, 2 \mathrm{H}), 3.50(\mathrm{~m}, 2 \mathrm{H}), 3.38(\mathrm{t}, 2 \mathrm{H}), 3.05(\mathrm{~m}, 2 \mathrm{H}), 1.36(\mathrm{~s}, 9 \mathrm{H}) ; \mathrm{MS}\left(\mathrm{ES}^{+}\right): \mathrm{m} / \mathrm{z} 418.28$ $(\mathrm{M}+\mathrm{H})^{+}$.

2-[2-[2-[2-(tert-Butoxycarbonylamino)ethoxy]ethoxy]ethoxy]-5-chloro-benzoic acid (14)

Methyl 2-[2-[2-[2-(tert-butoxycarbonylamino)ethoxy]ethoxy]ethoxy]-5-chloro-benzoate (3.00 g, $7.19 \mathrm{mmol})$ was dissolved in $\mathrm{EtOH}(30.0 \mathrm{~mL})$ and $1 \mathrm{M} \mathrm{LiOH}(9.80 \mathrm{~mL})$ was added. The mixture was stirred at $50{ }^{\circ} \mathrm{C}$ for $3.5 \mathrm{~h}$ and after cooling neutralized with citric acid. Ethanol was largely removed under reduced pressure, water was added and the product was extracted with dichloromethane. After drying the organic layer over sodium sulfate, removal of the solvent and drying under reduced pressure, the product was obtained as colorless solid $(2.81 \mathrm{~g}, 6.97 \mathrm{mmol}$, 97.0\% yield. ${ }^{1} \mathrm{H}$ NMR (400 MHz, DMSO-d6): $\delta 7.58$ (d, 1H), 7.49 (dd, 1H), $7.16(\mathrm{~d}, 1 \mathrm{H}), 6.73$ (br t, 1H), 5.75 (br s, 1H), $4.14(\mathrm{t}, 2 \mathrm{H}), 3.73(\mathrm{t}, 2 \mathrm{H}), 3.60(\mathrm{~m}, 2 \mathrm{H}), 3.50(\mathrm{~m}, 2 \mathrm{H}), 3.38(\mathrm{t}, 2 \mathrm{H})$, $3.05(\mathrm{~m}, 2 \mathrm{H}), 1.37(\mathrm{~s}, 9 \mathrm{H}) ; \mathrm{MS}\left(\mathrm{ES}^{+}\right): \mathrm{m} / \mathrm{z} 404.1(\mathrm{M}+\mathrm{H})^{+}$.

d) tert-butyl-(2-(2-(2-(4-chloro-2-((4-(N-(cyclohexylcarbamoyl) sulfamoyl)phenethyl) carbamoyl)phenoxy)ethoxy)ethoxy)ethyl)carbamate (10)

5-chloro-2-((2,2-dimethyl-4-oxo-3,8,11-trioxa-5-azatridecan-13-yl)oxy)benzoic acid (2.80 g, $7.21 \mathrm{mmol})$ and triethylamine $(1.05 \mathrm{~g}, 10.4 \mathrm{mmol})$ were dissolved in DCM (25 mL). Pivaloyl chloride $(1.00 \mathrm{~mL}, 11.6 \mathrm{mmol})$ in DCM $(4.50 \mathrm{~mL})$ was added dropwise at ambient temperature. After stirring for $40 \mathrm{~min}$, 4-dimethylamino-pyridine (135 mg, $1.10 \mathrm{mmol})$ ) and 1-[4-(2aminoethyl)phenyl] sulfonyl-3-cyclohexyl-urea $(2.26 \mathrm{~g}, 6.95 \mathrm{mmol})$ were added and the mixture was stirred for further $5 \mathrm{~h}$ at ambient temperature. After the reaction was deemed complete the solution was washed with $10 \%$ citric acid, aqueous $\mathrm{NaHCO}_{3}$ and dried with sodium sulfate. The solvent was removed in vacuo and the crude product purified by RP-HPLC using water/acetonitrile gradient on a C18 column. The acetonitrile was removed in vacuo and the aqueous phase extracted with DCM. The organic phase was washed with aqueous $\mathrm{NaHCO}_{3}$ and the DCM removed in vacuo yielding of the sulphonylurea 10 (3.18 g, $4.47 \mathrm{mmol}, 64.3 \%$ yield). ${ }^{1} \mathrm{H}$ NMR $\left(300 \mathrm{MHz}, \mathrm{CDCl}_{3}\right) \delta 8.15(\mathrm{~d}, J=2.8 \mathrm{~Hz}, 1 \mathrm{H}), 7.86(\mathrm{~d}, J=8.1 \mathrm{~Hz}, 2 \mathrm{H}), 7.38(\mathrm{~d}, 2 \mathrm{H})$, 
$7.34(\mathrm{dd}, J=2.7 \mathrm{~Hz}, 1 \mathrm{H}), 6.86(\mathrm{~d}, J=8.8 \mathrm{~Hz}, 1 \mathrm{H}), 6.44(\mathrm{~d}, J=6.7 \mathrm{~Hz}, 1 \mathrm{H}), 5.01(\mathrm{~s}, 1 \mathrm{H}), 4.22-$ $4.00(\mathrm{~m}, 4 \mathrm{H}), 3.72(\mathrm{q}, J=6.2 \mathrm{~Hz}, 3 \mathrm{H}), 3.65-3.44(\mathrm{~m}, 14 \mathrm{H}), 3.35-3.22(\mathrm{~m}, 4 \mathrm{H}), 3.03(\mathrm{t}, J=6.6$ $\mathrm{Hz}, 2 \mathrm{H}), 1.97-1.52(\mathrm{~m}, 7 \mathrm{H}), 1.43(\mathrm{~s}, 8 \mathrm{H}), 1.27(\mathrm{ddd}, J=30.6,17.3,9.2 \mathrm{~Hz}, 7 \mathrm{H}) .{ }^{13} \mathrm{C}$ NMR $(75$ $\left.\mathrm{MHz}, \mathrm{CDCl}_{3}\right) \delta 164.33,155.29,150.53,146.27,138.05,132.53,132.02,129.88,127.41,127.28$, 123.37, 114.58, 79.66, 77.16, 70.45, 70.36, 70.23, 68.89, 68.41, 49.23, 40.91, 40.28, 35.51, 33.12, 28.55, 25.48, 24.72. (HRMS, ESI): $\mathrm{m} / \mathrm{z}$ calculated for $[\mathrm{M}+\mathrm{H}]^{+} 711.2825$, found 711.2823 .

2-(2-(2-(2-aminoethoxy)ethoxy)ethoxy)-5-chloro- $N-(4-(N-($ cyclohexylcarbamoyl) sulfamoyl)phenethyl)benzamide (9)

Compound 10 (2.83 g, $3.98 \mathrm{mmol})$ was dissolved in DCM (45.0 mL). Trifluoroacetic acid (5.00 $\mathrm{mL}$ ) was added and the mixture is stirred for $1 \mathrm{~h}$ at ambient temperature. The reaction mixture was concentrated in vacuo. A mixture of acetonitrile/water $(1: 2,30 \mathrm{~mL})$ was added followed by $1.00 \mathrm{~N} \mathrm{HCl}(5.00 \mathrm{~mL})$, and the mixture freeze-dried. This procedure was repeated two times yielding the colorless solid 9 as hydrochloride salt $(2.37 \mathrm{~g}, 3.61 \mathrm{mmol}$, yield $90.7 \%)$. ${ }^{1} \mathrm{H}$ NMR $\left(300 \mathrm{MHz}, \mathrm{CD}_{3} \mathrm{OD}\right) \delta 7.92(\mathrm{~d}, J=8.4 \mathrm{~Hz}, 1 \mathrm{H}), 7.70(\mathrm{~d}, J=2.7 \mathrm{~Hz}, 1 \mathrm{H}), 7.51(\mathrm{~d}, J=8.4 \mathrm{~Hz}$, $1 \mathrm{H}), 7.44(\mathrm{dd}, J=8.9,2.8 \mathrm{~Hz}, 1 \mathrm{H}), 7.12(\mathrm{~d}, J=8.9 \mathrm{~Hz}, 1 \mathrm{H}), 4.29-4.21(\mathrm{~m}, 2 \mathrm{H}), 3.80-3.73(\mathrm{~m}$, 2H), $3.69(\mathrm{t}, J=5.2 \mathrm{~Hz}, 4 \mathrm{H}), 3.47-3.34(\mathrm{~m}, 1 \mathrm{H}), 3.13-3.07(\mathrm{~m}, 2 \mathrm{H}), 3.03(\mathrm{t}, J=6.8 \mathrm{~Hz}, 2 \mathrm{H})$, $1.83-1.50(\mathrm{~m}, 6 \mathrm{H}), 1.41-1.09(\mathrm{~m}, 4 \mathrm{H}) .{ }^{13} \mathrm{C} \mathrm{NMR}\left(75 \mathrm{MHz}, \mathrm{CD}_{3} \mathrm{OD}\right) \delta$ 167.28, 156.56, 153.00, 146.99, 139.78, 133.25, 131.01, 130.72, 128.80, 127.24, 125.81, 115.99, 70.17, 69.76, 68.07, 50.17, 49.00, 41.85, 40.55, 36.16, 33.78, 26.46, 25.76. (HRMS, ESI): $\mathrm{m} / \mathrm{z}$ calculated for $[\mathrm{M}+\mathrm{H}]^{+}$567.2039, found 567.2036.

4-((2-(2-(2-(4-chloro-2-((4-(N-(cyclohexylcarbamoyl)sulfamoyl)phenethyl)carbamoyl)

phenoxy)ethoxy)ethoxy)ethyl)amino)-4-oxobutanoic acid (12)

Compound $9(97.4 \mathrm{mg}, 150 \mu \mathrm{mol})$ was dissolved in a mixture of dioxane/DMF $(5: 1,5.00 \mathrm{~mL})$. After the addition of DIPEA $(110 \mu \mathrm{L}, 623 \mu \mathrm{mol})$ succinic anhydride $(15.1 \mathrm{mg}, 151 \mu \mathrm{mol})$ was added to the reaction. After stirring for $2 \mathrm{~h}$ at ambient temperature the reaction was judged to be complete by TLC control. The solvents were evaporated under reduced pressure and the crude product was acidified with $0.1 \mathrm{M} \mathrm{HCl}(15 \mathrm{~mL})$ solution and extracted with dichloromethane $(5 \times 30 \mathrm{~mL})$. The organic fractions were pooled and dried over anhydrous sodium sulfate. After evaporation of the solvent the crude product was purified by flash chromatography using dichloromethane/methanol (10:1) obtaining colorless solid (91.0 mg, $128 \mu \mathrm{mol}, 85.4 \%$ yield). ${ }^{1} \mathrm{H}$ NMR $\left(300 \mathrm{MHz}, \mathrm{CDCl}_{3}\right) \delta 8.18(\mathrm{t}, J=5.8 \mathrm{~Hz}, 1 \mathrm{H}), 8.12(\mathrm{~d}, J=2.8 \mathrm{~Hz}, 1 \mathrm{H}), 7.84(\mathrm{~d}, J=8.3 \mathrm{~Hz}$, 2H), $7.42(\mathrm{~d}, J=8.3 \mathrm{~Hz}, 2 \mathrm{H}), 7.34(\mathrm{dd}, J=8.8,2.8 \mathrm{~Hz}, 1 \mathrm{H}), 6.85(\mathrm{~d}, J=8.8 \mathrm{~Hz}, 1 \mathrm{H}), 6.61(\mathrm{~d}, J$ $=7.9 \mathrm{~Hz}, 1 \mathrm{H}), 6.52(\mathrm{t}, J=5.4 \mathrm{~Hz}, 1 \mathrm{H}), 4.13-4.06(\mathrm{~m}, 2 \mathrm{H}), 3.61-3.35(\mathrm{~m}, 12 \mathrm{H}), 3.02(\mathrm{~s}, 1 \mathrm{H})$, 2.68-2.62 (m, 2H), 2.48-2.44 (m, 2H), 1.80-1.77 (m, 2H), 1.66-1.11 (m, $10 \mathrm{H}) .{ }^{13} \mathrm{C} \mathrm{NMR}\left(\mathrm{CDCl}_{3}\right.$, $300 \mathrm{MHz}): \delta$ 177.14, 172.75, 164.54, 156.06, 155.36 , 152.12 , 146.41, 138.00, 132.64, 132.02, $130.11,127.38,123.42,114.71,70.44,70.17,69.84,68.94,68.53,49.42,41.04,39.48,35.59$, 33.01, 30.99, 29.91, 25.50, 24.71. (LRMS, ESI): $\mathrm{m} / \mathrm{z}$ calculated for $[\mathrm{M}-\mathrm{H}]^{-}$709.23, 711.23, found 709.5, 711.5. (HRMS, ESI): $\mathrm{m} / \mathrm{z}$ calculated for $[\mathrm{M}+\mathrm{H}]^{+}$711.2461, found 711.2461. 
5-chloro- $N-(4-(N-($ cyclohexylcarbamoyl $)$ sulfamoyl)phenethyl)-2-(2-(2-(2-methoxyethoxy) ethoxy)ethoxy)benzamide (6)

Compound $\mathbf{6}$ was synthesized according to the reaction sequence used to obtain compound $\mathbf{1 0}$ (S-2) using 1-(2-(2-iodoethoxy)ethoxy)-2-methoxy-ethane as the starting material, giving a colorless solid after 2 steps. ${ }^{1} \mathrm{H}$ NMR $\left(500 \mathrm{MHz}, \mathrm{DMSO}-d_{6}\right): \delta 10.29(\mathrm{~m}, 1 \mathrm{H}), 8.31(\mathrm{t}, 1 \mathrm{H}), 7.83$ $(\mathrm{d}, 2 \mathrm{H}), 7.73(\mathrm{~d}, 1 \mathrm{H}), 7.51(\mathrm{dd}, 1 \mathrm{H}), 7.48(\mathrm{~d}, 2 \mathrm{H}), 7.20(\mathrm{~d}, 1 \mathrm{H}), 6.32(\mathrm{~d}, 1 \mathrm{H}), 4.21(\mathrm{~m}, 2 \mathrm{H}), 3.68$ (m, 2H), 3.57 (q, 2H), 3.54-3.49 (br m, 4H), $3.46(\mathrm{~m}, 2 \mathrm{H}), 3.36(\mathrm{~m}, 2 \mathrm{H}), 3.18(\mathrm{~s}, 3 \mathrm{H}), 2.94(\mathrm{t}$, 2H), $1.64(\mathrm{~m}, 2 \mathrm{H}), 1.58(\mathrm{~m}, 2 \mathrm{H}), 1.48(\mathrm{~m}, 1 \mathrm{H}), 1.21(\mathrm{~m}, 2 \mathrm{H}), 1.19(\mathrm{~m}, 3 \mathrm{H}) ; \mathrm{MS}(\mathrm{ESI}): \mathrm{m} / \mathrm{z}$ $626.32(\mathrm{M}+\mathrm{H})^{+}$.

tert-butyl-(2-(2-(4-chloro-2-((4-(N-(cyclohexylcarbamoyl)sulfamoyl)phenethyl)carbamoyl) phenoxy)ethoxy)ethyl)carbamate (8)

Compound $\mathbf{8}$ was synthesized according to the reaction sequence used to obtain compound $\mathbf{1 0}$ (S-2) using tert-butyl N-[2-(2-iodoethoxy)ethyl]carbamate as starting material, giving a colorless solid in 2 steps. ${ }^{1} \mathrm{H}$ NMR (500 MHz, DMSO- $\left.d_{6}\right): \delta 10.30$ (br s, $\left.1 \mathrm{H}\right), 8.32(\mathrm{t}, 1 \mathrm{H}, J=2.5 \mathrm{~Hz}$ ), $7.82(\mathrm{~d}, 2 \mathrm{H}, J=8.3 \mathrm{~Hz}), 7.73(\mathrm{~d}, 1 \mathrm{H}, J=8.1 \mathrm{~Hz}), 7.51(\mathrm{dd}, 1 \mathrm{H}, J=8.1,3.4 \mathrm{~Hz}), 7.47(\mathrm{~d}, 2 \mathrm{H}, J=$ $2.7 \mathrm{~Hz}), 7.20(\mathrm{~d}, 1 \mathrm{H}, J=8.8 \mathrm{~Hz}), 6.79(\mathrm{br} \mathrm{t}, 1 \mathrm{H}), 6.30(\mathrm{~m}, 1 \mathrm{H}), 4.19(\mathrm{~m}, 2 \mathrm{H}), 3.65(\mathrm{~m}, 2 \mathrm{H}), 3.57$ $(\mathrm{q}, 2 \mathrm{H}, J=6.3 \mathrm{~Hz}), 3.39(\mathrm{t}, 2 \mathrm{H}, J=5.4 \mathrm{~Hz}), 3.08(\mathrm{~m}, 2 \mathrm{H}), 2.92(\mathrm{t}, 2 \mathrm{H}, J=6.0 \mathrm{~Hz}), 1.67-1.61(\mathrm{~m}$, $2 \mathrm{H}), 1.60-1.54(\mathrm{~m}, 2 \mathrm{H}), 1.52-1.44(\mathrm{br} \mathrm{m}, 1 \mathrm{H}), 1.33(\mathrm{~s}, 9 \mathrm{H}), 1.20-1.10(\mathrm{~m}, 5 \mathrm{H}) .{ }^{13} \mathrm{C}$ NMR $(75$ $\left.\mathrm{MHz}, \mathrm{CDCl}_{3}\right) \delta 164.34,163.96,159.70,155.25,142.27,135.28,132.62,130.15,127.48,127.33$, 114.50, 77.50, 70.27, 68.48, 68.34, 51.23, 49.41, 41.13, 40.35, 35.64, 33.17, 28.61, 25.54, 24.80, 24.36. (HRMS, ESI): $\mathrm{m} / \mathrm{z}$ calculated for $[\mathrm{M}+\mathrm{H}]^{+} 667.3563$, found 667.2567.

2-(2-(2-aminoethoxy)ethoxy)-5-chloro- $N-(4-(N-($ cyclohexylcarbamoyl $)$ sulfamoyl) phenethyl)benzamide (7)

The deprotection procedure applied to 10 (S-2) was used to convert tert-butyl-(2-(2-(4-chloro-2((4-(N-(cyclohexylcarbamoyl)sulfamoyl) phenethyl) carbamoyl)phenoxy) ethoxy)ethyl)carbamate 8 into the hydrochloride salt 7 yielding a colorless solid. ${ }^{1} \mathrm{H}$ NMR (500 MHz, DMSO- $\left.d_{6}\right): \delta$ 10.35 (br s, 1H), $8.33(\mathrm{t}, 1 \mathrm{H}), 7.84(\mathrm{~d}, 2 \mathrm{H}),, 7.75(\mathrm{~m}, 2 \mathrm{H}), 7.63(\mathrm{~d}, 1 \mathrm{H}), 7.51(\mathrm{dd}, 1 \mathrm{H}), 7.20$ (d, $2 \mathrm{H}), 6.40(\mathrm{~d}, 1 \mathrm{H}), 4.22(\mathrm{~m}, 2 \mathrm{H}), 3.73(\mathrm{~m}, 2 \mathrm{H}), 3.61(\mathrm{t}, 2 \mathrm{H}), 3.54(\mathrm{q}, 2 \mathrm{H}), 2.97(\mathrm{q}, 2 \mathrm{H}), 2.93(\mathrm{t}$, 2H), $1.68-1.55$ (br m, 4H), 1.48 (m, 1H), 1.20 (m, 2H), 1.11 (br m, 3H); MS (ESI): m/z 567.09 $(\mathrm{M}+\mathrm{H}){ }^{+} .{ }^{13} \mathrm{C}$ NMR $\left(75 \mathrm{MHz}, \mathrm{DMSO}-d_{6}\right) \delta 166.80,156.80,152.96,147.06,139.78,133.63$, $131.43,130.76,128.87,127.49,125.23,116.32,71.48,71.40,70.18,69.90,67.94,50.18,49.00$, 41.93, 40.59, 36.20, 33.80, 26.47, 25.77. (HRMS, ESI): m/z calculated for $[\mathrm{M}+\mathrm{H}]^{+} 611.2301$, found 611.2299 . 
2-(2-((2-(4-chloro-2-((4-(N-(cyclohexylcarbamoyl)sulfamoyl)phenethyl)carbamoyl)phenoxy) ethyl)amino)-2-oxoethoxy)acetic acid (11)

Compound 7 (97.4 mg, $150 \mu \mathrm{mol})$ was dissolved in a mixture of dioxane/DMF $(5: 1,5.00 \mathrm{~mL})$. After the addition of DIPEA $(110 \mu \mathrm{L}, 623 \mu \mathrm{mol})$, glutaric anhydride $(17.7 \mathrm{mg}, 132 \mu \mathrm{mol})$ was added to the reaction mixture. After stirring for $2 \mathrm{~h}$ at ambient temperature the reaction was judged to be complete by TLC. The solvents were evaporated under reduced pressure and the crude product was acidified with $0.1 \mathrm{M} \mathrm{HCl}(15 \mathrm{~mL})$ solution and extracted with dichloromethane $(5 \times 30 \mathrm{~mL})$. The organic fractions were pooled and dried over anhydrous sodium sulfate. After evaporation of the solvent the crude product was purified by flash chromatography using dichloromethane/methanol (10:1) as eluent obtaining colorless solid (91.0 mg, $128 \mu \mathrm{mol}, 85.4 \%$ yield). ${ }^{1} \mathrm{H}$ NMR (300 MHz, DMSO-d6) $\delta 8.97(\mathrm{br} \mathrm{s}, 1 \mathrm{H}), 8.19$ (t, $J=$ $5.8 \mathrm{~Hz}, 1 \mathrm{H}), 7.78(\mathrm{~d}, J=7.9 \mathrm{~Hz}, 2 \mathrm{H}), 7.70(\mathrm{~d}, J=2.9 \mathrm{~Hz}, 1 \mathrm{H}), 7.47(\mathrm{dd}, J=8.8,2.9 \mathrm{~Hz}, 1 \mathrm{H})$, $7.42(\mathrm{~d}, J=7.9 \mathrm{~Hz}, 2 \mathrm{H}), 7.15(\mathrm{~d}, J=8.9 \mathrm{~Hz}, 1 \mathrm{H}), 4.12(\mathrm{t}, J=4.6 \mathrm{~Hz}, 2 \mathrm{H}), 3.90(\mathrm{~d}, J=11.9 \mathrm{~Hz}$, $4 \mathrm{H}$ ), 3.55 (h, $J=8.9,7.6 \mathrm{~Hz}, 4 \mathrm{H}), 3.37$ (t, $J=6.4 \mathrm{~Hz}, 2 \mathrm{H}), 3.23$ (q, $J=6.2 \mathrm{~Hz}, 3 \mathrm{H}), 2.89$ (t, $J=$ $6.9 \mathrm{~Hz}, 2 \mathrm{H}), 1.77-1.50(\mathrm{~m}, 4 \mathrm{H}), 1.46(\mathrm{~d}, J=11.1 \mathrm{~Hz}, 1 \mathrm{H}), 1.09(\mathrm{~m}, 5 \mathrm{H}) .{ }^{13} \mathrm{C}$ NMR $(75 \mathrm{MHz}$, DMSO) $\delta 174.40,170.73,164.11,155.69,152.59,145.12,140.20,132.45,130.47,129.76$, 127.59, 125.43, 125.06, 116.29, 69.42, 69.08, 68.78, 48.68, 40.84, 38.48, 35.23, 33.15, 25.81, 25.03. (HRMS, ESI): $\mathrm{m} / \mathrm{z}$ calculated for $[\mathrm{M}+\mathrm{H}]^{+} 639.1886$, found 639.1879 .

2-(2-aminoethoxy)-N-(4-(N-(cyclohexylcarbamoyl)sulfamoyl)phenethyl)-5-fluorobenzamide (5)

a) Methyl 5-fluoro-2- hydroxybenzoate $(2.50 \mathrm{~g}, 14.7 \mathrm{mmol})$, tert-butyl $\mathrm{N}-(2-$ hydroxyethyl)carbamate $(2.55 \mathrm{~g}, 15.8 \mathrm{mmol})$, and triphenylphosphane $(3.85 \mathrm{~g}, 14.7 \mathrm{mmol})$ were dissolved in dry THF $(75 \mathrm{~mL})$. Diisopropyl-azodicarboxylate $(2.97 \mathrm{~g}, 14.7 \mathrm{mmol})$ was added at 0 ${ }^{\circ} \mathrm{C}$, stirred for $30 \mathrm{~min}$ and then the reaction mixture was allowed to warm to ambient temperature. After $6 \mathrm{~h}$ the solvent volume was decreased under reduced pressure to $50 \mathrm{~mL}$ and the precipitate was filtered off and washed with ethyl acetate. After evaporating the solvents, the residue was purified by flash chromatography using ethylacetate/heptane (1:2) as mobile phase. The fractions containing the product were pooled and evaporated giving methyl 2-[2-(tertbutoxycarbonylamino)ethoxy]-5-fluoro-benzoate as colorless oil (1.39 g, $4.44 \mathrm{mmol}, 30.2 \%$ yield). ${ }^{1} \mathrm{H}$ NMR (500 Mhz, DMSO- $\left.d 6\right) \quad \delta 7.43(\mathrm{~m}, 1 \mathrm{H}), 7.40-7.36(\mathrm{br} \mathrm{m}, 1 \mathrm{H}), 7.19(\mathrm{~m}, 1 \mathrm{H}), 6.82$ $(\mathrm{t}, 1 \mathrm{H}) 4.01(\mathrm{t}, 2 \mathrm{H}), 3.80(\mathrm{~s}, 3 \mathrm{H}), 3.28(\mathrm{~m}, 2 \mathrm{H}) 1.34(\mathrm{~s}, 9 \mathrm{H}) ; \mathrm{MS}(\mathrm{ES}+): \mathrm{m} / \mathrm{z} 336.13[\mathrm{M}+\mathrm{Na}]^{+}$.

b) The reaction sequence used to convert compound 14 to 9 (S-2) was used to convert methyl 2[2-(tert-butoxycarbonylamino)ethoxy]-5-fluoro-benzoate to 2-(2-aminoethoxy)-N-(4-(N(cyclohexyl carbamoyl)sulfamoyl)phenethyl)-5-fluorobenzamide (5) (yield 84.3\%). ${ }^{1} \mathrm{H}$ NMR $\left(300 \mathrm{MHz}, \mathrm{CD}_{3} \mathrm{OD}\right) \delta 7.85(\mathrm{~d}, \mathrm{~J}=8.3 \mathrm{~Hz}, 2 \mathrm{H}), 7.42(\mathrm{~d}, \mathrm{~J}=8.3 \mathrm{~Hz}, 2 \mathrm{H}), 7.34-7.28(\mathrm{~m}, 1 \mathrm{H})$, $7.20(\mathrm{dd}, \mathrm{J}=7.7,3.1 \mathrm{~Hz}, 1 \mathrm{H}), 7.14(\mathrm{dd}, \mathrm{J}=9.1,4.3 \mathrm{~Hz}, 1 \mathrm{H}), 4.22(\mathrm{t}, \mathrm{J}=5.0 \mathrm{~Hz}, 2 \mathrm{H}), 3.70(\mathrm{t}, \mathrm{J}=$ $6.6 \mathrm{~Hz}, 2 \mathrm{H}), 3.48-3.33(\mathrm{~m}, 1 \mathrm{H}), 3.13-3.04(\mathrm{~m}, 1 \mathrm{H}), 2.99(\mathrm{t}, \mathrm{J}=8.3,4.7 \mathrm{~Hz}, 2 \mathrm{H}), 1.86-1.50$ $(\mathrm{m}, 4 \mathrm{H}), 1.43-1.04(\mathrm{~m}, 6 \mathrm{H}) .{ }^{13} \mathrm{C}$ NMR $\left(75 \mathrm{MHz}, \mathrm{CD}_{3} \mathrm{OD}\right) \delta 160.24,157.05,153.24,130.42$, 
127.96, 119.79, 119.47, 117.45, 117.10, 67.83, 50.12, 49.00, 41.68, 40.12, 36.04, 34.22, 26.64, 25.99. (HRMS, ESI): $\mathrm{m} / \mathrm{z}$ calculated for $[\mathrm{M}+\mathrm{H}]^{+}$507.2072, found 507.2067.

Dendrimer Synthesis. PAMAM-G5 was purchased from Sigma-Aldrich. ${ }^{1} \mathrm{H}$ NMR $(300 \mathrm{MHz}$, $\mathrm{D}_{2} \mathrm{O}$ ) $\delta 3.39$ (br s), 3.29 (br s), 3.24 (s), 3.22 (s), 3.15-3.11 (m), 2.82 (br s), 2.62 (br s), 2.47-2.40 (m). $\left(\right.$ MALDI-TOF $\left.{ }^{+}\right):[\mathrm{M}+\mathrm{H}]^{+} 25450$.

PAMAM G5-RhX $X_{5}$ (probe A)

PAMAM-G5 5\% solution in $\mathrm{MeOH}(2.0 \mathrm{~mL})$ was evaporated under reduced pressure and dried in vacuo for $1 \mathrm{~h}$. Colorless oil $(79 \mathrm{mg}, 3.1 \mu \mathrm{mol})$ was re-dissolved in dry DMSO $(20 \mathrm{~mL})$. RhodamineX-NHS $(9.8 \mathrm{mg}, 15 \mu \mathrm{mol})$ was dissolved in dry DMF $(7.0 \mathrm{~mL})$ and added drop wise to PAMAM-G5 solution under vigorous stirring for $15 \mathrm{~min}$. The solution was stirred for 12 hours at which point water $(20 \mathrm{~mL})$ was added slowly. The product was transferred to a 6-8 $\mathrm{kDa}$ cutoff dialysis bag and dialyzed against water $(5.0 \mathrm{~L})$ for $48 \mathrm{~h}$. The water was changed at 1, 4, 12 and $24 \mathrm{~h}$. After freeze-drying fluffy violet product $(79.2 \mathrm{mg}, 2.8 \mu \mathrm{mol}, 91.0 \%$ yield) was obtained. ${ }^{1} \mathrm{H}$ NMR (300 MHz, $\mathrm{D}_{2} \mathrm{O}$ ) $\delta 3.39$ (br s), 3.29 (br s), 3.24 (s), 3.22 (s), 3.15-3.11 (m), 2.82 (br s), 2.62 (br s), 2.47-2.40 (m). (MALDI-TOF ${ }^{+}$): $[\mathrm{M}+\mathrm{H}]^{+} 27998$.

PAMAM G5-RhX $X_{5}-\mathrm{Glib}_{2}$ (probe B)

4-((2-)-(2-(4-chloro-2-((4- $(\mathrm{N}-$ (cyclohexylcarbamoyl)sulfamoyl)phenethyl)carbamoyl)phenoxy)ethoxy)ethoxy)ethyl)amino)-4oxobutanoic acid (12) $(1.0 \mathrm{mg}, 1.4 \mu \mathrm{mol})$ was dissolved in dry DMF $(3.0 \mathrm{~mL})$ and solutions containing DIPEA $(0.72 \mu \mathrm{L}, 4.2 \mu \mathrm{mol})$ and HATU $(0.82 \mathrm{mg}, 2.2 \mu \mathrm{mol})$ were added successively. The solution was stirred for $10 \mathrm{~min}$ and then added very slowly drop wise to the solution of probe A (PAMAM G5-RhX $)(13 \mathrm{mg}, 0.48 \mu \mathrm{mol})$ in dry DMSO $(6.0 \mathrm{~mL})$. The reaction was quenched with water $(3.0 \mathrm{~mL})$ after $16 \mathrm{~h}$ and dialyzed $(6-8 \mathrm{kDa}$ membrane cutoff) against water $(5.0 \mathrm{~L})$. The dialysis vehicle was changed at 1, 4, 12 and $24 \mathrm{~h}$. After $48 \mathrm{~h}$ the product was freeze-dried. The product was re-dissolved in water $(0.5 \mathrm{~mL})$ and applied to a short G-20 size-exclusion column. The fractions containing the product were pooled, freeze-dried giving a fluffy violet product $\left(8.3 \mathrm{mg}, 0.28 \mu \mathrm{mol}, 58 \%\right.$ yield). ${ }^{1} \mathrm{H} \mathrm{NMR}\left(300 \mathrm{MHz}, \mathrm{D}_{2} \mathrm{O}\right) \delta 8.39$ (d, $J=4.1 \mathrm{~Hz}), 8.10$ (d, $J=8.5 \mathrm{~Hz}), 7.61(\mathrm{br} \mathrm{s}), 7.52(\mathrm{br} \mathrm{s}, 1 \mathrm{H}), 7.25$ (dd, $J=8.5,4.3 \mathrm{~Hz}), 7.16$ (br s), 3.39 (br s), 3.29 (br s), 3.24 (s), 3.22 (s), 3.15-3.11 (m), 2.82 (br s), 2.62 (br s), 2.47-2.40 (m). $\left(\right.$ MALDI-TOF $\left.{ }^{+}\right):[\mathrm{M}+\mathrm{H}]^{+} 29154$.

PAMAM G5-RhX ${ }_{5}-\mathrm{Glib}_{5}$ (probe $\left.\mathbf{C}\right)$

4-((2-(2-(2-(4-chloro-2-((4-(N-(cyclohexylcarbamoyl)sulfamoyl)phenethyl)carbamoyl)

phenoxy)ethoxy)ethoxy)ethyl)amino)-4-oxobutanoic acid (12) $(2.2 \mathrm{mg}, 3.1 \mu \mathrm{mol})$ was dissolved in dry DMF $(3.0 \mathrm{~mL})$. containing DIPEA $(1.6 \mu \mathrm{L}, 9.3 \mu \mathrm{mol})$ and HATU $(1.8 \mathrm{mg}, 4.74 \mu \mathrm{mol})$. The solution was stirred for $10 \mathrm{~min}$ and then very slowly drop wise added to the solution of probe A (PAMAM G5- $\left.\mathrm{RhX}_{5}\right)(13 \mathrm{mg}, 0.48 \mu \mathrm{mol})$ in dry DMSO $(6.0 \mathrm{~mL})$. The reaction was 
quenched with water $(3.0 \mathrm{~mL})$ after $16 \mathrm{~h}$ and dialyzed $(6-8 \mathrm{kDa}$ membrane cutoff) against water $(5.0 \mathrm{~L})$. The dialysis vehicle was changed at $1,4,12$ and $24 \mathrm{~h}$. After $48 \mathrm{~h}$ the product was freezedried. The product was re-dissolved in water $(0.5 \mathrm{~mL})$ and applied to a short G-20 size-exclusion column. The fractions containing the product were pooled, freeze-dried and fluffy violet product (9.4 mg, $0.31 \mu \mathrm{mol}, 65 \%$ yield) obtained. ${ }^{1} \mathrm{H}$ NMR $\left(300 \mathrm{MHz}, \mathrm{D}_{2} \mathrm{O}\right) \delta 8.39(\mathrm{~d}, J=4.1 \mathrm{~Hz}), 8.10$ (d, $J=8.5 \mathrm{~Hz}$ ), 7.61 (br s), 7.52 (br s, $1 \mathrm{H}), 7.25$ (dd, $J=8.5,4.3 \mathrm{~Hz}$ ), 7.16 (br s), 3.39 (br s), 3.29 (br s), 3.24 (s), 3.22 (s), 3.15-3.11 (m), 2.82 (br s), 2.62 (br s), 2.47-2.40 (m). (MALDI-TOF ${ }^{+}$): $[\mathrm{M}+\mathrm{H}]^{+} 31062$.

\section{PAMAM G5-RhX $X_{5}-G^{-G i b}{ }_{15}$ (probe D)}

4-((2-(2-(2-(4-chloro-2-((4-(N-(cyclohexylcarbamoyl)sulfamoyl)phenethyl)carbamoyl)phenoxy) ethoxy)ethoxy)ethyl)amino)-4-xobutanoic acid (12) $(7.0 \mathrm{mg}, 9.9 \mu \mathrm{mol})$ was dissolved in dry DMF $(10.0 \mathrm{~mL})$ containing DIPEA $(5.1 \mu \mathrm{L}, 29.8 \mu \mathrm{mol})$ and HATU $(5.8 \mathrm{mg}, 15.3 \mu \mathrm{mol})$. The solution was stirred for $10 \mathrm{~min}$ and then very slowly drop wise added to the solution of probe A (PAMAM G5-RhX $)(13.5 \mathrm{mg}, 0.48 \mu \mathrm{mol})$ in dry DMSO $10.0 \mathrm{~mL})$. The reaction was quenched with water $(3.0 \mathrm{~mL})$ after $16 \mathrm{~h}$ and dialyzed $(6-8 \mathrm{kDa}$ membrane cutoff) against water $(5.0 \mathrm{~L})$. The dialysis vehicle was changed at $1,4,12$ and $24 \mathrm{~h}$. After $48 \mathrm{~h}$ the product was freeze-dried. The product was re-dissolved in water $(0.5 \mathrm{~mL})$ and applied to a short G-20 size-exclusion column. The fractions containing the product were pooled, freeze-dried yielding a fluffy violet product $\left(7.1 \mathrm{mg}, 0.18 \mu \mathrm{mol}, 38 \%\right.$ yield). ${ }^{1} \mathrm{H}$ NMR $\left(300 \mathrm{MHz}, \mathrm{D}_{2} \mathrm{O}\right) \delta 8.39(\mathrm{~d}, J=4.1 \mathrm{~Hz}), 8.10$ (d, $J=8.5 \mathrm{~Hz}$ ), 7.61 (br s), 7.52 (br s, 1H), 7.25 (dd, $J=8.5,4.3 \mathrm{~Hz}$ ), 7.16 (br s), 3.39 (br s), 3.29 (br s), 3.24 (s), 3.22 (s), 3.15-3.11 (m), 2.82 (br s), 2.62 (br s), 2.47-2.40 (m). (MALDI-TOF ${ }^{+}$): $[\mathrm{M}+\mathrm{H}]^{+} 38600$.

\section{Biology}

Cell lines. HeLa cells (American Type Culture Collection-LGC Promochem, Teddington, Middlesex, UK) and PANC-1 cells (Human pancreatic carcinoma, epithelial-like cell line) were cultured in DMEM containing $25 \mathrm{mmol} / \mathrm{L}$ glucose and $10 \%$ calf serum. MIN6 cells were cultured in DMEM medium containing 15\% heat-inactivated fetal calf serum and $70 \mu \mathrm{mol} / 1 \beta$ mercaptoethanol. MIN6 cells were plated on coverslips coated with Matrigel from 804G cellcultures. Cells were kept at $37{ }^{\circ} \mathrm{C}$ in a humidified incubator, gassed with air and $6.0 \% \mathrm{CO}_{2}$, fed at 2 day intervals and passed once a week.

Islet cells. Islets were isolated from the pancreas of adult mice and multi-organ donors, as previously described ${ }^{(45,46)}$, in accordance with the regulations of our institutional and state committees on animal welfare (authorisation $\mathrm{N}^{\circ} 1034 / 3550 / 2$ ), and on utilization of human samples. The isolated islets were washed twice in phosphate-buffered saline without $\mathrm{Mg}^{2+}$ and $\mathrm{Ca}^{2+}$ (PBS0Ca), and then incubated in the same buffer for $10 \mathrm{~min}$. Cells were then dispersed by repeated pipetting of the islets in PBS0Ca supplemented with $1 \mathrm{mg} / \mathrm{ml}$ trypsin (DIFCO , Detroit, Mi) for $2.5 \mathrm{~min}$ at $37^{\circ} \mathrm{C}$. The dispersion was stopped by the addition of $10 \mathrm{ml}$ ice-cold RPMI 
supplemented with 10\% FCS (RPMI). The resulting suspension which comprised mostly single cells was centrifuged for $5 \mathrm{~min}$ at $140 \mathrm{~g}$. The pellet was diluted to obtain a density of $10^{6}$ cells per $100 \mu \mathrm{l}$ RPMI, plated on matrigel-coated coverslips, and cultured for 3 days before the experiments.

RT-PCR. Total RNA was extracted from HeLa, PANC-1 and MIN6 cells using Trizol (Invitrogen), as recommended by the manufacturer. The RNA quality was controlled using a laser Agilent 2100 bioanalyser. A total of $1 \mu \mathrm{g}$ total RNA was reverse-transcribed using $200 \mathrm{U}$ Reverse transcriptase Superscript II (Invitrogen), $60 \mathrm{ng} / \mu 1$ random hexamer primers (Promega) and $500 \mu \mathrm{M}$ each dNTP mix (Invitrogen). The mixture was heated to $70{ }^{\circ} \mathrm{C}$ for $10 \mathrm{~min}$ and quickly chilled on ice. First strand buffer $(5 \times), 10 \mathrm{mM}$ dithiothreitol and $200 \mathrm{U}$ Superscript II Reverse transcriptase (Invitrogen) were then added. The samples were heated to $25^{\circ} \mathrm{C}$ for 10 min, to $42{ }^{\circ} \mathrm{C}$ for $50 \mathrm{~min}$ and to $70{ }^{\circ} \mathrm{C}$ for a $15 \mathrm{~min}$ inactivation. $0.5 \mathrm{U}$ RNase $\mathrm{H}$ (Roche) was then added for $20 \mathrm{~min}$ at $37^{\circ} \mathrm{C}$. For PCR, a 1:10 and 4:10 dilution of the cDNAs of cyclophilin and SUR1 were used respectively, in a mix containing dNTP mix, buffer $10 \mathrm{X}$, and Taq polymerase (Invitrogen), and $166 \mathrm{nM}$ of each primer. The amplification protocol consisted of a 5 min initial activation of the Taq polymerase at $95{ }^{\circ} \mathrm{C}, 30$ cycles of denaturation at $95{ }^{\circ} \mathrm{C}$ for $1 \mathrm{~min}$, annealing at $65{ }^{\circ} \mathrm{C}$ for $1 \mathrm{~min}$ and elongation at $72{ }^{\circ} \mathrm{C}$ for $1 \mathrm{~min}$. The following primers were used: for cyclophiline, 5'-GGT CAA CCC CAC CGT GTT CT-3' (F) and 5'-AGA CTG AGT GGC TGG ATG GCA-3' (R); for SUR1, 5'-ATG AGG AAG AGG AGG AAG AG-3' (F) and 5'-TCG ATG GTG TTA CAG TCA GA-3' (R). The PCR was performed using the Thermocycler T1 system (Biometra, Göttingen, Germany). PCR products were separated on a $2 \%$ agarose gel containing ethidium bromide and cDNA was visualized under UV.

Cell-Labeling Assay. After 3 days of culture, cell lines and primary cells were exposed for $1 \mathrm{~h}$, at either 4 or $22{ }^{\circ} \mathrm{C}$, to $1 \mu \mathrm{M}$ the different probes mentioned above, dissolved in a Krebs-Ringer bicarbonate buffer, $\mathrm{pH}$ 7.4. At the end of the incubation, the cultures were fixed in $4.0 \%$ paraformaldehyde, cover slipped, and examined with a LSM700 confocal laser scanning microscope (Zeiss, Oberkochen, Germany).

Competition Assay. MIN6 cells were plated in $35 \mathrm{~mm}$ dishes at the density of $0.5 \times 10^{5}$ cells per $2 \mathrm{~mL}$ DMEM medium. After 3 days, each cultures dish was exposed for $1 \mathrm{~h}$ at room temperature to $0.3 \mu \mathrm{Ci}{ }^{3} \mathrm{H}$-glibenclamide (Perkin Elmer Inc., MA, US) diluted in Krebs-Ringer bicarbonate buffer. Thereafter, increasing concentrations of either glibenclamide, glibenclamide derivatives or dendrimer probes containing glibenclamide derivatives were added for $1 \mathrm{~h}$ at room temperature. After 5 washes in KRB, the cells were extracted for $30 \min$ in $0.50 \mathrm{~N} \mathrm{NaOH}$, scraped off the culture support, mixed with a scintillation liquid (Picofluor 15, PerkinElmer, Waltham, Massachusets, USA), and evaluated in a beta-counter Beckman LS 6000TA (Beckman Couler, Fullertown, California, USA). IC50 values were defined as the concentration of the compound displacing $50 \%$ of ${ }^{3} \mathrm{H}$-glibenclamide. 
Cell viability. MIN6 cells were plated in 96-well plates at the density of $3 \times 10^{4}$ cells in $2 \mathrm{ml}$ DMEM medium containing $15 \%$ heat-inactivated fetal calf serum and $70 \mu \mathrm{mol} / 1 \quad \beta$ mercaptoethanol (DMEM). The medium was changed on the second day. On the third day, cells were exposed for $1 \mathrm{~h}$, at either 22 or $37^{\circ} \mathrm{C}$, to one of the probes or glibenclamide derivatives as described above. After 2 washes with PBS ( $\mathrm{pH} 7.4)$, cultures were incubated in DMEM supplemented with MTT $(0.5 \mathrm{mg} / \mathrm{mL})$, for $4 \mathrm{~h}$ at $37^{\circ} \mathrm{C}$. Thereafter, the medium was removed, formazan microcrystals were dissolved in $100 \%$ DMSO, and the culture microplates shaken for $15 \mathrm{~min}$ at room temperature. The absorbance of each well was determined using a spectrophotometer at $550 \mathrm{~nm}$. Controls were provided by cultures exposed to DMSO under the same conditions tested for the probes.

Insulin secretion. MIN6 cells were plated at the density of $5 \times 10^{5}$ cells per $2.0 \mathrm{ml}$ DMEM. Three days later, the cultures were pre-incubated for $30 \mathrm{~min}$ at $37^{\circ} \mathrm{C}$ in a $\mathrm{KRB}$ containing $1.4 \mathrm{mM}$ and $16.8 \mathrm{mM}$ glucose, and then incubated for $1 \mathrm{~h}$ in KRB-supplemented with the indicated concentration of glucose, with or without one of the imaging probes. The medium was collected, centrifuged for $20 \mathrm{~min}$ at $3500 \mathrm{~g}$, and the supernatant frozen at $-20{ }^{\circ} \mathrm{C}$ for insulin assay. The cells were then extracted for $24 \mathrm{~h}$ at $4{ }^{\circ} \mathrm{C}$ in acid-ethanol and the extracts also frozen for determination of total insulin content, as determined by radioimmunoassay ${ }^{(45)}$. Insulin release was expressed as percentage of the total insulin content.

In vivo characterization of the probe. Normoglycemic, control mice were injected within the retro-orbital venous plexus with $1 \mathrm{mg} / \mathrm{kg}$ body weight of either the glibenclamide-containing probe $\mathrm{C}$ or the control probe $\mathrm{A}$. The probes were tagged by $\mathrm{Cy} 5$ for fluorescence detection. Mice were sacrificed 1,2, 4, 12 and $24 \mathrm{~h}$ later. The pancreas, liver, and kidneys were harvested and fixed overnight by immersion in $4.0 \%$ PFA in phosphate buffer at $4{ }^{\circ} \mathrm{C}$. The organs were rinsed for $15 \mathrm{~h}$ in $25 \%$ sucrose, embedded in OCT compound (Tissue-Tek, Sakura), and cryosectioned at $7 \mu \mathrm{m}$ thickness. Sections were mounted on microscope slides, and labeled for insulin and glucagon using a guinea pig polyclonal antibody (Ventrex 675, diluted 1/200) and a rabbit polyclonal antibody (DAKO, diluted 1/100), respectively. Secondary antibodies were anti-guinea pig Igs coupled to Dylight 405 (1/800, Jackson Laboratories), and anti-rabbit Igs coupled to Alexa488 (1/500, Molecular Probes) for insulin and glucagon immunolabeling, respectively. Sections were coversliped, and photographed with a Zeiss Axiophot fluorescence microscope or a LSM700 Zeiss confocal microscope.

Statistical analysis. Data were analyzed using either paired Student's t-test, assuming a 2-tailed distribution, or one-way ANOVA (GraphPad Prism 4 software; GraphPad Software Inc., San Diego, USA). The error bars represent standard deviation. P values $<0.05$ were considered as statistically significant. 


\section{RESULTS AND DISCUSSION}

Synthesis of glibenclamide derivatives as targeting ligands. Glibenclamide (Fig. 1) contains no functional group amenable for covalent attachment to nanocarriers. Therefore, the molecule was modified with functional group to allow for conjugation, without significantly loss of affinity to SUR1. Based on previous studies ${ }^{(39,40)}$, and the established structure-activity relationship requirements for binding, affinity and selectivity for SUR1, we introduced conjugation-ready functional groups at two distinct positions of the distal phenyl ring of glibenclamide (Fig. 1, Table 1). The functionalized derivatives were all tested for binding affinity.

Most reported methods for affinity testing to SUR1 have been developed with membrane extracts of cells transitionally overexpressing SUR1, which cannot differentiate the interactions of sulphonylureas with the SUR1 localized in different parts of the cells and which overestimate ligand-receptor binding ${ }^{(39)}$. Therefore, we have set-up a novel glibenclamide competition assay in living MIN6 cells, which natively express SUR1. Using this assay, we found that native glibenclamide had an $\mathrm{IC}_{50}=140 \mathrm{nM}$, which is higher than previously reported for membrane extracts $(40,47)$. Our data further showed that most modifications of native glibenclamide significantly increased this value, reflecting a reduced affinity of the modified sulphonylureas for SUR1 (Table 1). Thus, the introduction of a functional amino group at the 4'-phenyl position decreased the affinity by 2 -fold in derivative $\mathbf{2}$, and any further modification at this position, as exemplified by derivatives 3 and $\mathbf{4}$, resulted in a complete loss $\left(\mathrm{IC}_{50}>10000 \mathrm{nM}\right.$ ) of affinity to MIN6 cells.

Derivatives containing a linker with a conjugation-ready group at the methoxy group of glibenclamide were far superior. Thus, the $t$-Boc-protected derivative 8 displayed an excellent competition with glibenclamide, with $\mathrm{IC}_{50}$ of $204 \mathrm{nM}$, and derivative $\mathbf{1 0}$ featured the unprecedented $\mathrm{IC}_{50}$ of $71 \mathrm{nM}$, which is 2 -fold better than that of native glibenclamide. 


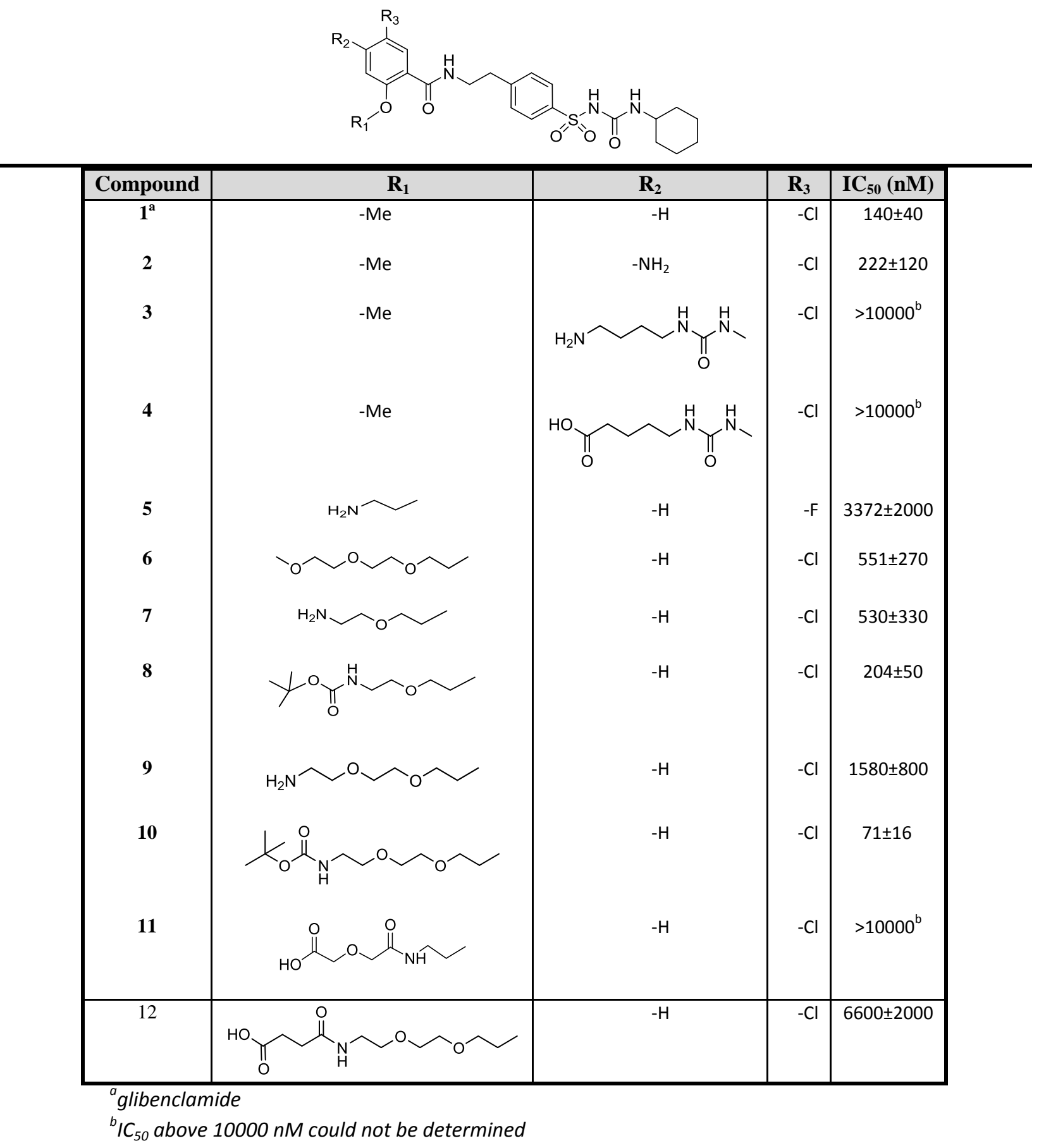

Table 1. Structures and affinities to SUR1 of glibenclamide and its derivatives. 
The lipophilic $t$-butyl carbamoyl group of compound $\mathbf{1 0}$ is favorably positioned for additional hydrophobic interactions with the SUR1 receptor, since the corresponding PEGylated compound 6 only displayed an $\mathrm{IC}_{50}$ of $551 \mathrm{nM}$ (Table 1). A 20 fold drop in affinity was observed when derivative $\mathbf{1 0}$ was deprotected to give derivative $\mathbf{9}$. Still, the affinity of the latter molecule was by far better than that of compound $\mathbf{3}$, in which the linker was attached to the 4'-phenyl position, identifying the methoxy group of glibenclamide as a favorable site for modifications. Derivative 9 was therefore reacted with succinic anhydride to obtain derivative 12, which carried a terminal carboxylic group. We hypothesized that the poor affinity of compounds $\mathbf{1 1}$ and $\mathbf{1 2}$ was a consequence of unfavorable repulsive interactions between the negatively charged carboxyl group and the receptor. However, it was assumed that this loss of affinity would be compensated by removing the negative charge upon conjugation to a nanocarrier and the by multivalency effect. Therefore, compound $\mathbf{1 2}$ was chosen for the synthesis of targeted multivalent probes.

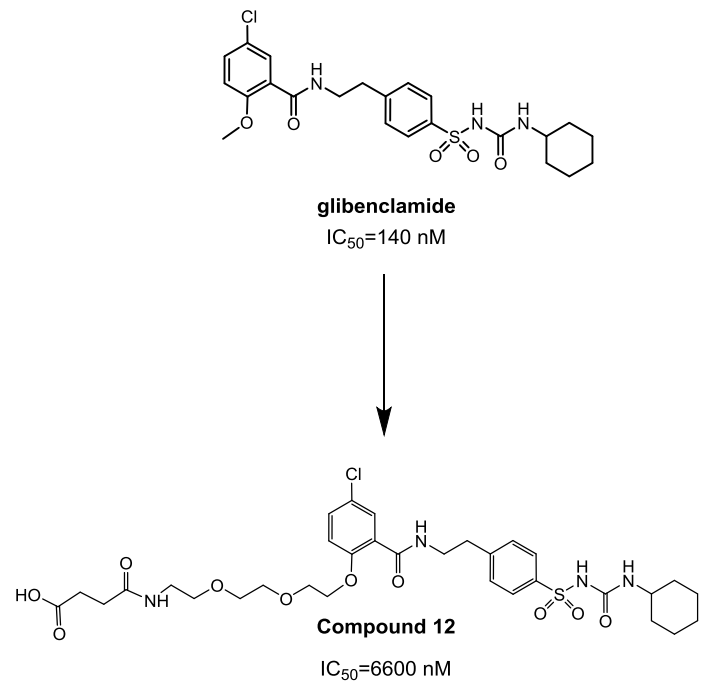

Fig. 1. Glibenclamide (top) has no functional groups amenable for conjugation. Compound $\mathbf{1 2}$ (bottom) was developed to allow conjugation to PAMAM dendrimers. Affinity to SUR1 is greatly reduced.

Design and synthesis of fluorescent probes. To achieve multimerization of glibenclamide, we choose as carriers the $5^{\text {th }}$ generation polyamidoamine PAMAM) dendrimers. These are tree-like macromolecules with 110 surface amino groups, which allow for a quantifiable attachment of multiple targeting moieties and reporter tags ${ }^{(48)}$. The size of PAMAM dendrimers is about 5.4 $\mathrm{nm}$ in diameter, small enough for the extravasation from the blood circulation to the sites of interest and for fast internalization once multivalent binding has taken place. Combined with a prolonged residence time on the target cells, this internalization ensures a sizable signal to noise ratio. 

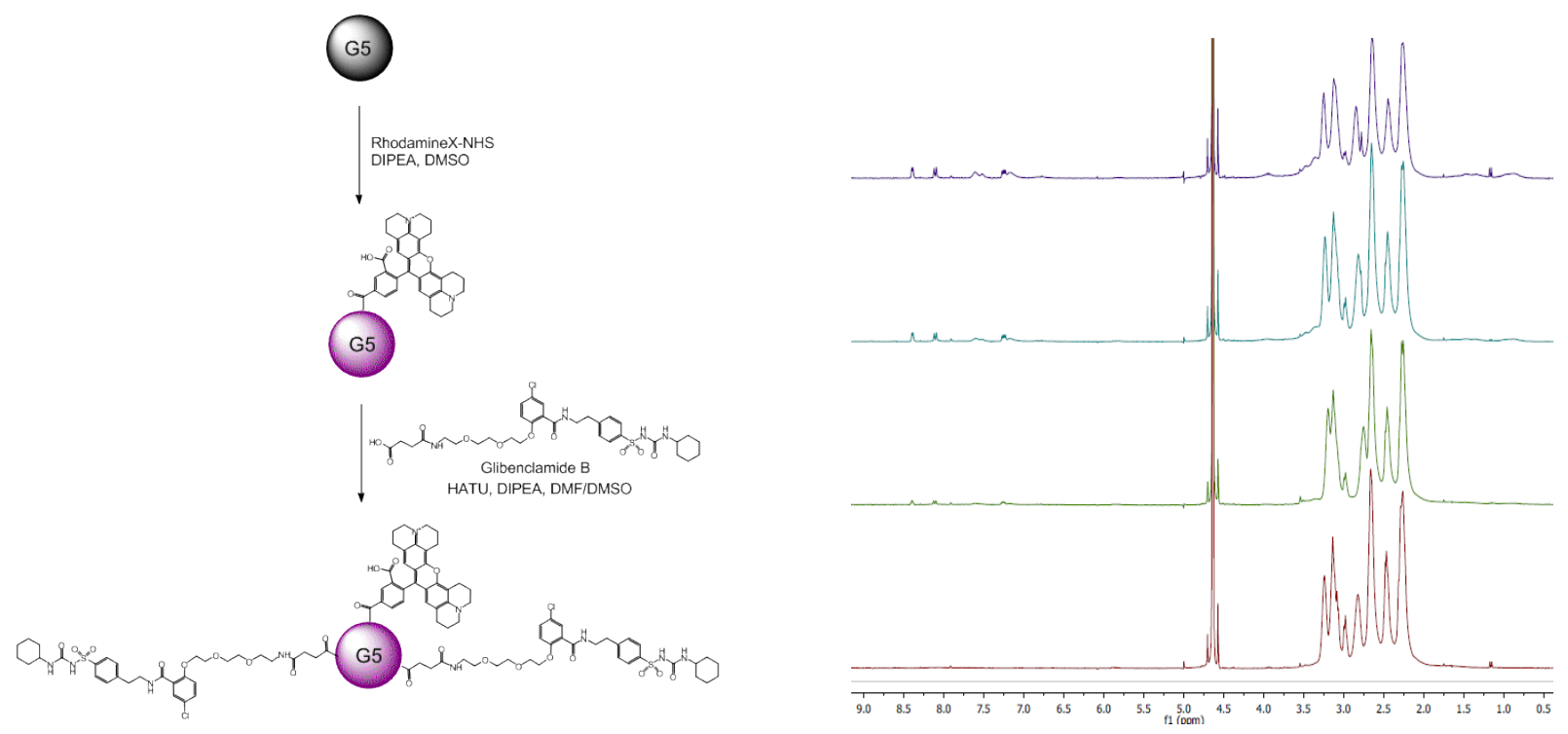

Fig. 2. General synthesis of PAMAM-rhodamine-X-glibenclamide conjugates (left) and ${ }^{1} \mathrm{H}$ NMR spectra of conjugate probes with increasing glibenclamide loading of $0,2,5,15$ glibenclamide ligands $\mathbf{1 2}$ per dendrimer from bottom to top (right).

The synthesis of the probes began with the attachment of rhodamine-X-NHS to the PAMAM-G5 backbone to allow for fluorescence imaging (Fig. 2). After activation with HATU/DIPEA, the glibenclamide derivative 12 was conjugated to PAMAM dendrimers in a reliable and repeatable way, thus allowing good control of ligand loading. The final probes were characterized by NMR and MALDI-MS to determine the payload of both rhodamineX and the targeting moiety $\mathbf{1 2}$, which was imperative to establish a correlation between multivalency and avidity.

The synthesis of tightly binding multivalent inhibitors is highly empirical, due to many interplaying factors including the number of ligands, the inter-ligand distances, the distances between ligands and carrier, and the flexibility of linkers ${ }^{(49)}$. In contrast to entropy, the enthalpy of interactions in multivalent system is additive, since the multiple ligands are individually attached to a carrier or are tethered to it by a linker. To minimize the entropic penalty of flexible linkers, we incorporated a very short linker into derivative 12 (Fig. 2).

Avidity of the multivalent probes. ${ }^{3} \mathrm{H}$-glibenclamide competition assays demonstrated increased avidities of the multivalent probes compared to the monovalent compounds (Table1, Table 2, and Fig. 3). The avidity increased almost 6-fold, from 875 to $166 \mathrm{nM}$ when the loading of ligand 12 was increased from 2 to 5 glibenclamide moieties per dendrimer in probes $\mathbf{B}$ and $\mathbf{C}$, respectively. Further increasing the glibenclamide load to 15 moieties (probe D) did not provide the same gain in avidity, presumably due to steric hindrance between targeting moieties or to mismatch between the densities of surface ligands and receptors. With an $\mathrm{IC}_{50}=66 \mathrm{nM}$, probe $\mathbf{D}$ exhibited the best affinity to SUR1, even surpassing the affinity of native glibenclamide. Higher loadings of the polymeric carriers resulted in increased tendency for aggregation and decreased 
solubility under physiological conditions or pharmaceutically acceptable solvents. Control probe A, which was void of ligands to SUR1, did not show affinity (>10000 nM) to MIN6 cells.

\begin{tabular}{cccc} 
probe & $\begin{array}{c}\text { number of } \\
\text { rhodamine-X }\end{array}$ & $\begin{array}{c}\text { number of } \\
\text { glibenclamide }^{\mathbf{a}}\end{array}$ & $\mathbf{I C}_{\mathbf{5 0}}(\mathbf{n M})$ \\
\hline glibenclamide & - & - & $140 \pm 40$ \\
A & 5 & 0 & $>10000$ \\
B & 5 & 2 & $875 \pm 39$ \\
C & 5 & 5 & $116 \pm 44$ \\
D & 5 & 15 & $66 \pm 30$ \\
\hline
\end{tabular}

Table 2. The multivalecy effect. Avidity of probes A-D to SUR1 increases dramatically as more glibenclamide is attached to the dendrimers. Probe $\mathbf{C}$ displayed high avidity and suitable physico-chemical properties.

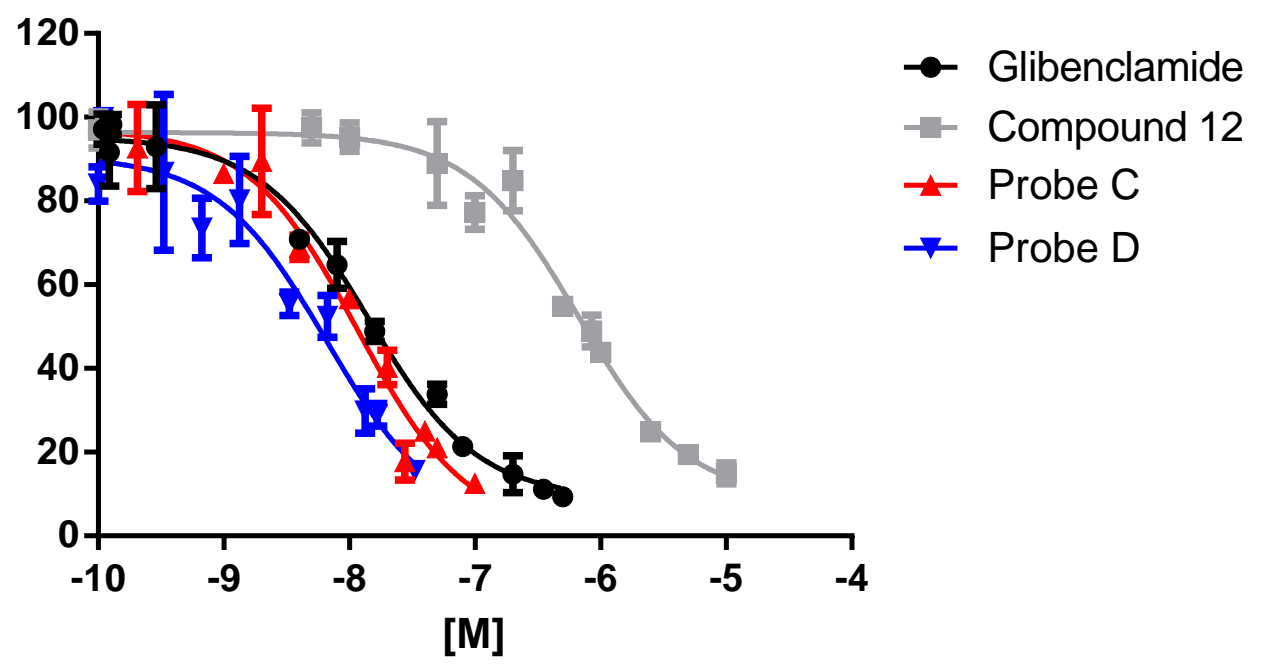

Fig. 3. Whole cell ${ }^{3} \mathrm{H}$-glibenclamide competition assay. Glibenclamide derivative $\mathbf{1 2}$ (gray) shows a significant loss of affinity towards SUR1. PAMAM-RhX-glibenclamide probes C and D (red and blue, respectively) recover the avidity through multivalent interactions with the receptor and display higher affinity than glibenclamide (black).

Cell binding. To assess the specificity of the multivalent probes, we compared HeLa and PANC1 cell lines, which do not express SUR1 (Fig. 4A) to MIN6 cells, which express these receptors and display glucose-dependent insulin-secretion. Probes B, C and $\mathbf{D}$ showed specific staining of 
MIN6 cells, but not of HeLa and PANC-1 cells. Given that the avidity for SUR1 of probe D was counterbalanced by a decrease in water solubility, we choose to test probe $\mathbf{C}$, which was freely soluble in physiological media in all other experiments.

First, probe internalization was studied by incubating MIN6 cells at different temperatures (S-5). At $4{ }^{\circ} \mathrm{C}$, the fluorescent probe was mainly located at the membrane, whereas, at room temperature, it labelled both the membrane and the cytoplasm, indicating active internalization. Most importantly, probes $\mathbf{B}$ and $\mathbf{C}$ displayed very limited non-specific staining of HeLa (Fig. 4B) and PANC-1 cells (Fig. 4C). Likely, this spurious labeling can be attributed to the positive surface charges of the probes, as confirmed by the control probe $\mathbf{A}$ which was void of glibenclamide ligands, and minimally labeled the three cell lines we tested. We then tested binding to primary cells from mouse and human islets and found a specific labeling of insulincontaining cells (Fig. 4E and 4F; S-3 and S-4). Probes displayed a binding near the cell membrane and in a lesser extent to the cytoplasm. Furthermore, alpha-cells of murine islets were not stained by probe $\mathbf{C}$ (Fig. 4E white arrow). 


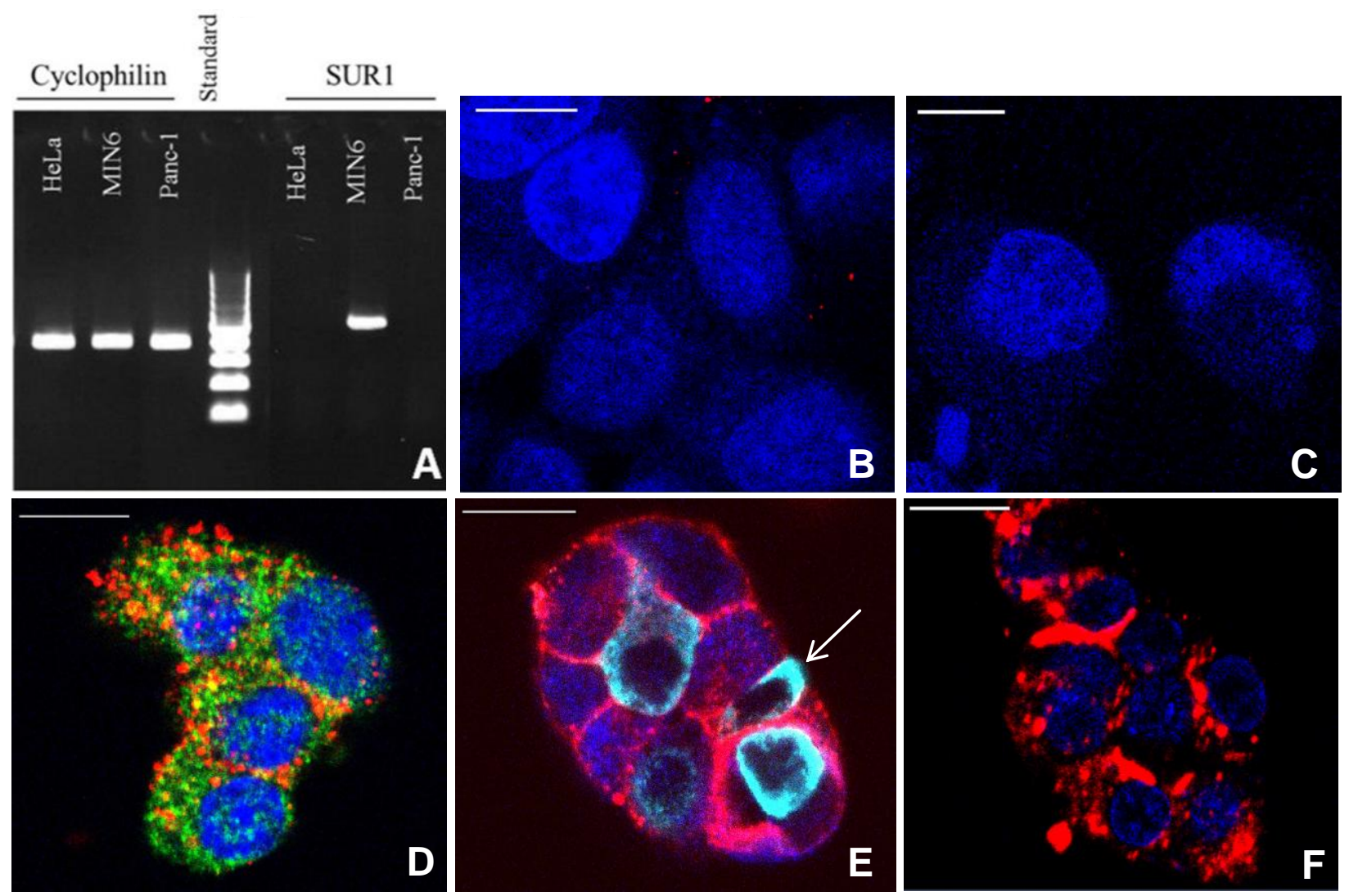

Fig. 4. Binding specificity in living cells. RT-PCR analysis showed that SUR1 is specifically expressed in MIN6, but not in HeLa and PANC-1 cells (A). Confocal fluorescence microscopy shows low unspecific binding of probe $\mathbf{C}$ to control cell lines HeLa (B) and PANC-1 (C) respectively. Specific binding of probe $\mathbf{C}$ to MIN6 cells (D), as well as to primary beta-cells obtained from pancreatic murine (E) and human islets (F) respectively. Images are merged and show cell nuclei stained with DAPI (blue), insulin (green), glucagon (turquoise) and probe $\mathbf{C}$ containing rhodamine-X staining (red). Scale bar $=10 \mu \mathrm{m}$.

$\mathbf{E}$ 


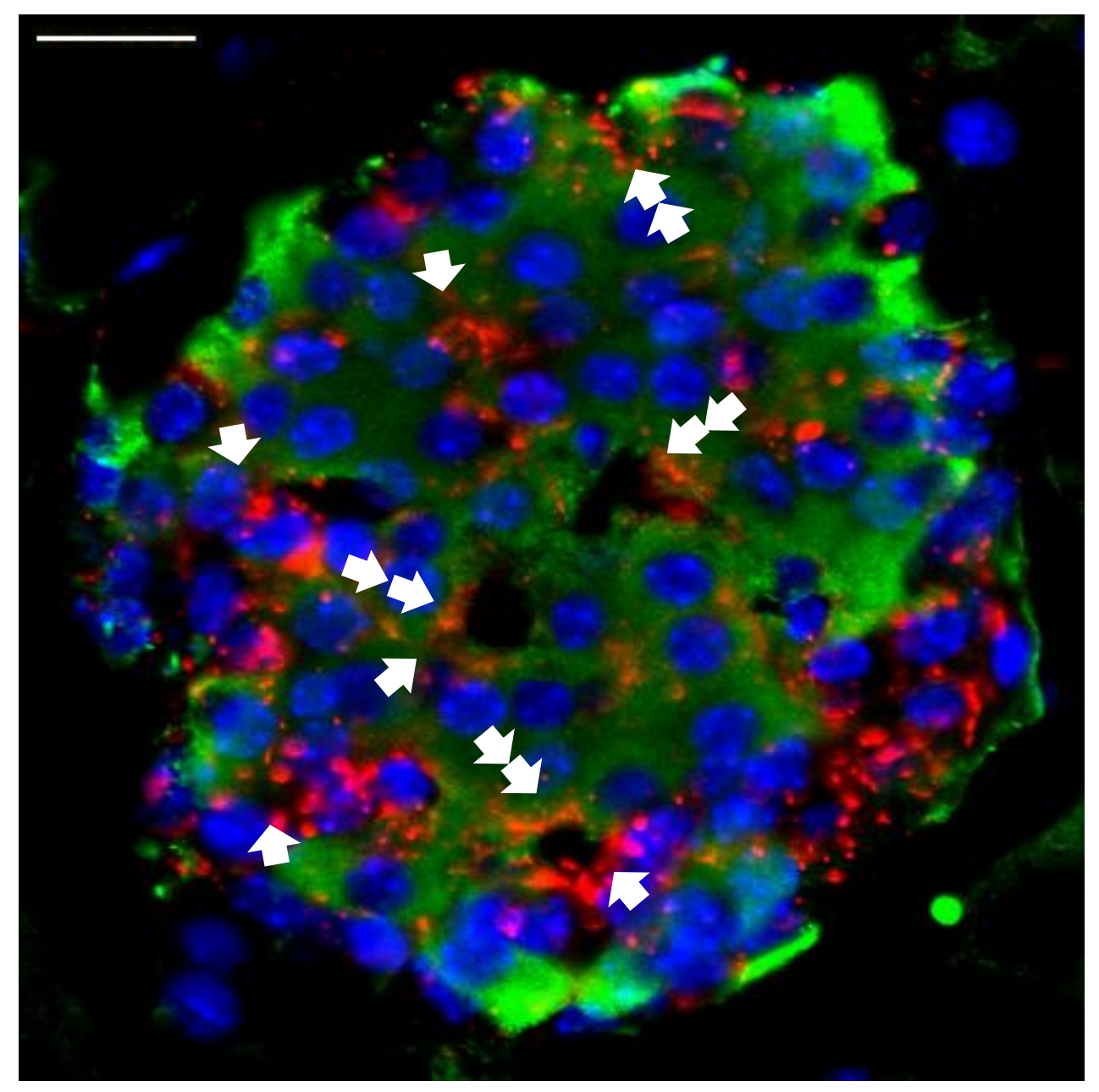

Fig. 5. Confocal microscopy image of murine islet after in vivo injection of probe C. Single arrows show islet vessel labelling and double arrows beta-cell periphery labelling. Cell nuclei stained with DAPI (blue), insulin (green) and probe $\mathbf{C}$ containing Cy5 staining (red). Scale bar = $20 \mu \mathrm{m}$

Effects of probes on insulin secretion. Sulphonylureas bind SUR1 on pancreatic beta-cells and inhibit ATP-dependent $\mathrm{K}^{+}$-channels causing the depolarization of the cells and a subsequent insulin release. To assess whether the imaging probes containing modified glibenclamide affected the function of the beta-cells, we tested the insulin secretion of MIN6 during one hour incubation in the presence of $1 \mu \mathrm{M}$ probe $\mathbf{C}$, and either 1.40 or $16.8 \mathrm{mM}$ glucose (Fig. 6B). As expected from its low affinity for SUR1, glibenclamide derivative $\mathbf{1 2}$ did not alter insulin secretion in the presence of both low and high glucose concentrations. Both glibenclamide derivative and and probe $\mathbf{C}$ showed increased insulin secretion in the presence of a high glucose concentration $(\$ \S: \mathrm{P}<0.01, \S \S \S$ : $\mathbf{P} 0.001)$. Interestingly, probe $\mathbf{C}$ also displayed increased insulin secretion at low glucose $(*: \mathrm{P}<0.05)$. The total content of insulin was found unchanged 
under these conditions (S-6). At $1 \mu \mathrm{M}$ concentration, this probe also did not affect cell viability as shown by MTT assay (Fig. 6).
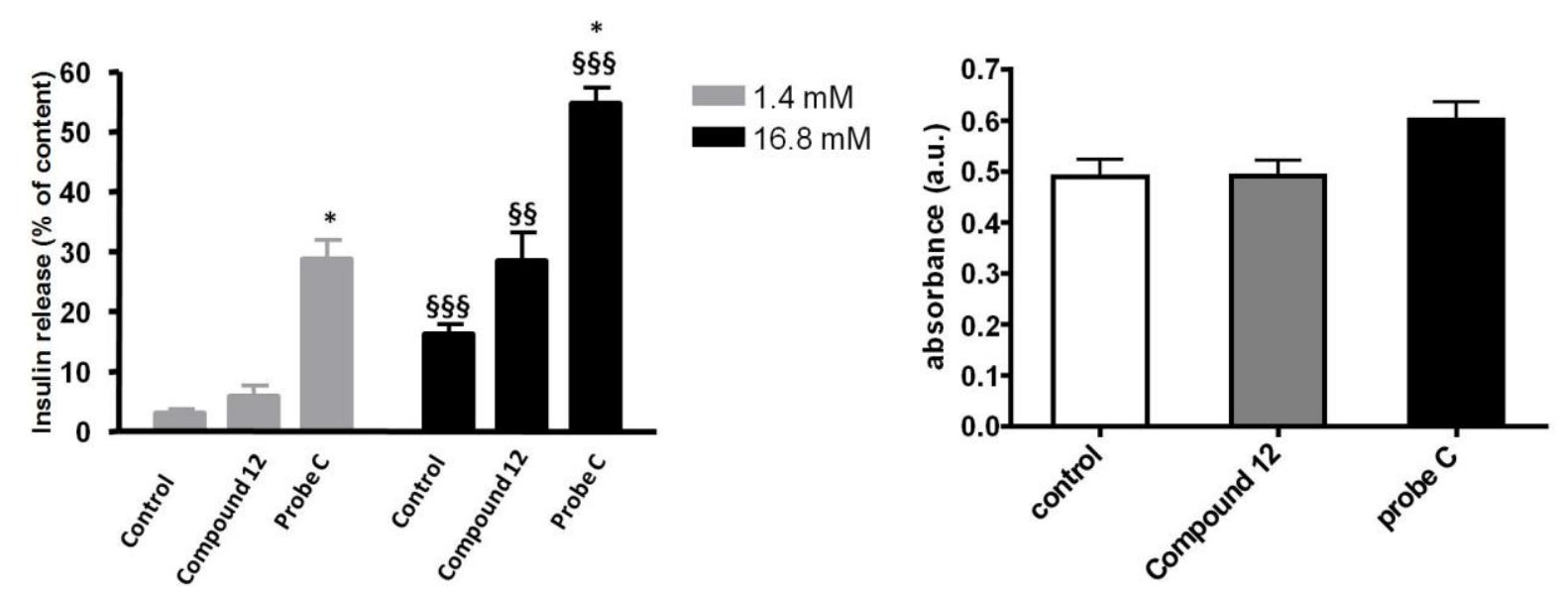

Fig. 6. Activity (left) and cytotoxicity (right) of compound $\mathbf{1 2}$ and probe $\mathbf{C}$. Probe $\mathbf{C}$ triggers significant release of insulin from MIN6 cells (left). Probe $\mathbf{C}$ and glibenclamide derivative compound 12 do not display any significant cytotoxicity towards MIN6 cells (right).

In vivo islet labelling. One, 4,8 and $24 \mathrm{~h}$ after the i.v. injection of non-targeted probe $\mathrm{A}$, which did not contain glibenclamide derivatives, a minimal Cy5 fluorescence staining was observed at the levels of vessels of both exocrine acinar lobes, and endocrine pancreatic islets (Fig. 7A-C). Targeted probe $\mathrm{C}$ containing multivalent glibenclamide similarly stained the exocrine pancreas, but much more distinctly outlined many islet vessels (Fig.7 D-F). Thus, $12 \mathrm{~h}$ after its i.v. injection, the islets clearly stood out over the poorly labelled background of the pancreas lobes (Fig. 7 D-F). Higher magnification, confocal views of the islets, revealed that probe $\mathrm{C}$ also marginally stained the periphery of some of the insulin-containing beta-cells (Fig. 5), in a spotted pattern reminiscent of that observed in vitro (Fig. 4). The data provide the first evidence that at least some of the glibenclamide-carrying probe reached its cellular target, even though to levels significantly lower than those binding, presumably non-specifically, to pancreatic vessels. Recent studies have shown that PAMAM dendrimers beyond $4^{\text {th }}$ generation could be potentially toxic, particularly affecting the complement system ${ }^{(50)}$. Therefore lower generations of PAMAM dendrimers might offer the same benefits for multivalent probes but with reduced toxicity. 


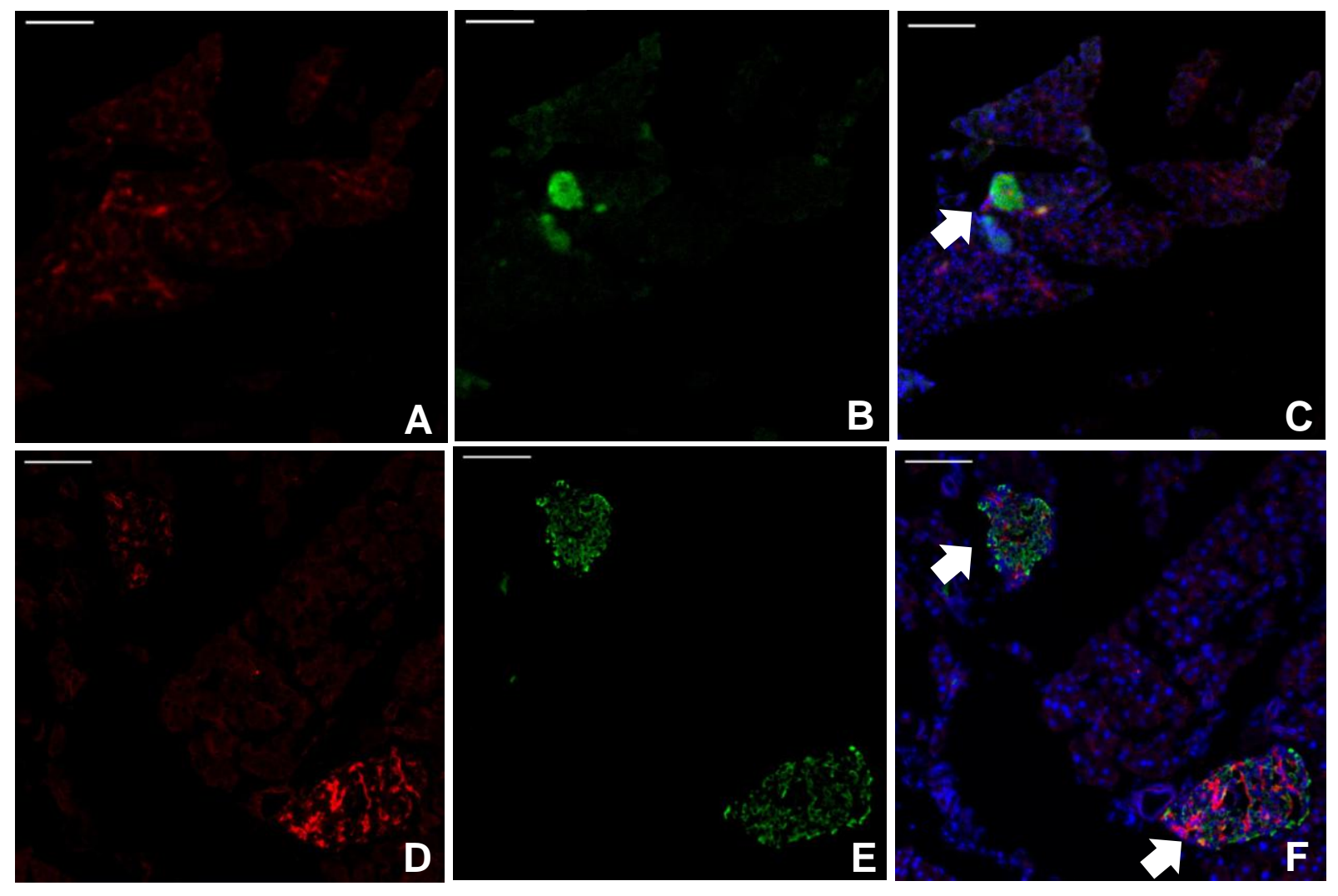

Fig. 7. In vivo labeling of murine pancreas. $12 \mathrm{~h}$ after an i.v. injection of a probe. Control Probe A resulted in a minimal staining of the exocrine pancreas $(A-C)$ and few islet vessels $(C)$. Probe $\mathbf{C}$ targeting the islets (white arrows), as confirmed by insulin immunostaining (panel E) made them clearly visible using the red channel fluorescence (D) Images $\mathrm{C}$ and $\mathrm{F}$ are merged and show cell nuclei stained with DAPI (blue), insulin (green) and probe $\mathbf{C}$ containing Cy5 staining (red). Scale bar $=100 \mu \mathrm{m}$. 


\section{CONCLUSIONS}

We designed and developed a series of glibenclamide ligands amenable for conjugation onto dendrimers, which we used to synthesize fluorescently labeled multivalent probes. Compared to the previously tested low molecular weight glibenclamide ligands, these probes featured an increased avidity for SUR1and image islets in vitro and in vivo. The data provide the proof of principle that a multivalent beta-cell-specific ligand would significantly improve the performance of an islet-imaging probe. Future developments should aim at developing probes that somehow bypass the endothelial binding, e.g. by further modifying the glibenclamide derivatives, refining the multimerization levels, and/or identifying the most appropriate times for imaging after the probe administration, to achieve a more substantial and specific labeling of individual endocrine islet cell types. Given that the dendrimer-multivalent structure can be tagged by other reporters than the fluorochromes used in this study, the strategy could be adapted to various imaging modalities, a requisite for its future clinical translation.

\section{- ACKNOWLEDGEMENTS}

We would like to thank the Mass spectrometry center of the University of Geneva for performing the MALDI-TOF AND high-resolution ESI experiments. This work was supported, by grants from the Swiss National Science Foundation (310000-109402, CR32I3_129987, 205320_138309; 205321_126834, CR32I3_147018), the Juvenile Diabetes Research Foundation (40-2011-11, 99-2012-775, 5-2012-281), the European Union (BETAIMAGE, 222980; BETATRAIN 289932), and the Fondation Romande pour le Diabète. The work leading to this publication has received support from the Innovative Medicines Initiative Joint Undertaking under grant agreement $\mathrm{n}^{\circ} 155005$ (IMIDIA), resources of which are composed of financial contribution from the European Union's Seventh Framework Programme (FP7/2007-2013) and EFPIA companies' in kind contribution.

\section{- REFERENCES}

1. Danaei, G., Finucane, M. M., Lin, J. K., Singh, G. M., Paciorek, C. J., Cowan, M. J., Farzadfar, F., Stevens, G. A., Lim, S. S., Riley, L. M., Ezzati, M., and C, G. B. M. R. F. (2011)

National, regional, and global trends in systolic blood pressure since 1980: systematic analysis of 
health examination surveys and epidemiological studies with 786 country-years and 5.4 million participants, Lancet 377, 568-577.

2. Stefan, Y., Orci, L., Malaisselagae, F., Perrelet, A., Patel, Y., and Unger, R. H. (1982) Quantitation of Endocrine Cell Content in the Pancreas of Non-Diabetic and Diabetic Humans, Diabetes 31, 694-700.

3. Weir, G. C., Bonnerweir, S., and Leahy, J. L. (1990) Islet Mass and Function in Diabetes and Transplantation, Diabetes 39, 401-405.

4. Barker, J. M. (2006) Clinical review: Type 1 diabetes-associated autoimmunity: Natural history, genetic associations, and screening, J Clin Endocr Metab 91, 1210-1217.

5. Eisenbarth, G. S. (2007) Update in type 1 diabetes, J Clin Endocr Metab 92, 2403-2407. 6. Haller, M. J., Gottlieb, P. A., and Schatz, D. A. (2007) Type 1 diabetes intervention trials 2007: where are we and where are we going?, Current opinion in endocrinology, diabetes, and obesity 14, 283-287.

7. Medarova, Z., and Moore, A. (2009) MRI as a tool to monitor islet transplantation, Nat Rev Endocrinol 5, 444-452.

8. Evgenov, N. V., Medarova, Z., Dai, G. P., Bonner-Weir, S., and Moore, A. (2006) In vivo imaging of islet transplantation, Nat Med 12, 144-148.

9. Malaisse, W. J. (2005) Non-invasive imaging of the endocrine pancreas (review), International journal of molecular medicine 15, 243-246.

10. Souza, F., Freeby, M., Hultman, K., Simpson, N., Herron, A., Witkowsky, P., Liu, E., Maffei, A., and Harris, P. E. (2006) Current progress in non-invasive imaging of beta cell mass of the endocrine pancreas, Curr Med Chem 13, 2761-2773. 
11. Virostko, J., Henske, J., Vinet, L., Lamprianou, S., Dai, C. H., Radhika, A., Baldwin, R. M., Ansari, M. S., Hefti, F., Skovronsky, D., Kung, H. F., Herrera, P. L., Peterson, T. E., Meda, P., and Powers, A. C. (2011) Multimodal image coregistration and inducible selective cell ablation to evaluate imaging ligands, P Natl Acad Sci USA 108, 20719-20724.

12. Malaisse, W. J., Zhang, Y., Louchami, K., Sharma, S., Dresselaers, T., Himmelreich, U., Novotny, G. W., Mandrup-Poulsen, T., Waschke, D., Leshch, Y., Thimm, J., Thiem, J., and Sener, A. (2012) (19)F-heptuloses as tools for the non-invasive imaging of GLUT2-expressing cells, Archives of biochemistry and biophysics 517, 138-143.

13. Cline, G. W., Zhao, X. J., Jakowski, A. B., Soeller, W. C., and Treadway, J. L. (2011) Islet-selectivity of G-protein coupled receptor ligands evaluated for PET imaging of pancreatic beta-cell mass, Biochem Bioph Res Co 412, 413-418.

14. Singhal, T., Ding, Y. S., Weinzimmer, D., Normandin, M. D., Labaree, D., Ropchan, J., Nabulsi, N., Lin, S. F., Skaddan, M. B., Soeller, W. C., Huang, Y. Y., Carson, R. E., Treadway, J. L., and Cline, G. W. (2011) Pancreatic Beta Cell Mass PET Imaging and Quantification with [(11)C]DTBZ and [(18)F]FP-(+)-DTBZ in Rodent Models of Diabetes, Mol Imaging Biol 13, 973-984.

15. Kung, M. P., Hou, C., Goswami, R., Ponde, D. E., Kilbourn, M. R., and Kung, H. F. (2007) Characterization of optically resolved 9-fluoropropyl-dihydrotetrabenazine as a potential PET imaging agent targeting vesicular monoamine transporters, Nucl Med Biol 34, 239-246.

16. Sweet, I. R., Cook, D. L., Lernmark, A., Greenbaum, C. J., Wallen, A. R., Marcum, E. S., Stekhova, S. A., and Krohn, K. A. (2004) Systematic screening of potential beta-cell imaging agents, Biochem Bioph Res Co 314, 976-983. 
17. Simpson, N. R., Souza, F., Witkowski, P., Maffei, A., Raffo, A., Herron, A., Kilbourn, M., Jurewicz, A., Herold, K., Liu, E., Hardy, M. A., Van Heertum, R., and Harris, P. E. (2006) Visualizing pancreatic beta-cell mass with [11C]DTBZ, Nucl Med Biol 33, 855-864.

18. Andralojc, K. M., Brom, M., Joosten, L., Oyen, W., Boerman, O., and Gotthardt, M. (2010) In vivo visualization of transplanted islets in rat by SPECT imaging with 111In-Exendin3, Eur J Nucl Med Mol I 37, S307-S307.

19. Reiner, T., Thurber, G., Gaglia, J., Vinegoni, C., Liew, C. W., Upadhyay, R., Kohler, R. H., Li, L., Kulkarni, R. N., Benoist, C., Mathis, D., and Weissleder, R. (2011) Accurate measurement of pancreatic islet beta-cell mass using a second-generation fluorescent exendin-4 analog, P Natl Acad Sci USA 108, 12815-12820.

20. Wu, Z., Todorov, I., Li, L., Bading, J. R., Li, Z. B., Nair, I., Ishiyama, K., Cocher, D., Conti, P. E., Fraser, S. E., Shively, J. E., and Kandeel, F. (2011) In Vivo Imaging of Transplanted Islets with Cu-64-DO3A-VS-Cys(40)-Exendin-4 by Targeting GLP-1 Receptor, Bioconjugate Chem 22, 1587-1594.

21. Wild, D., Behe, M., Wicki, A., Storch, D., Waser, B., Gotthardt, M., Keil, B., Christofori, G., Reubi, J. C., and Macke, H. R. (2006) [Lys(40) (Ahx-DTPA-In-111)NH2]exendin-4, a very promising ligand for glucagon-like peptide-1 (GLP-1) receptor targeting, J Nucl Med 47, 20252033.

22. Kelsey, G. (2007) Genomic imprinting - Roles and regulation in development, Endocrin Dev 12, 99-112.

23. Kutlu, B., Naamane, N., Berthou, L., and Eizirik, D. L. (2004) New approaches for in silico identification of cytokine-modified beta cell gene networks, Ann Ny Acad Sci 1037, 41-58. 
24. Ortsater, H., and Bergsten, P. (2006) Protein profiling of pancreatic islets, Expert Rev Proteomic 3, 665-675.

25. Sparre, T., Larsen, M. R., Heding, P. E., Karlsen, A. E., Jensen, O. N., and Pociot, F. (2005) Unraveling the pathogenesis of type 1 diabetes with proteomics - Present and future directions, Mol Cell Proteomics 4, 441-457.

26. Vinet, L., Lamprianou, S., Babic, A., Lange, N., Thorel, F., Herrera, P. L., Montet, X., and Meda, P. (2015) Targeting GLP-1 receptors for repeated magnetic resonance imaging differentiates graded losses of pancreatic beta cells in mice, Diabetologia 58, 304-312.

27. Mikkola, K., Yim, C. B., Fagerholm, V., Ishizu, T., Elomaa, V. V., Rajander, J., Jurttila, J., Saanijoki, T., Tolvanen, T., Tirri, M., Gourni, E., Behe, M., Gotthardt, M., Reubi, J. C., Macke, H., Roivainen, A., Solin, O., and Nuutila, P. (2014) 64Cu- and 68Ga-labelled [Nle(14),Lys(40)(Ahx-NODAGA)NH2]-exendin-4 for pancreatic beta cell imaging in rats, $M o l$ Imaging Biol 16, 255-263.

28. Brom, M., Joosten, L., Frielink, C., Boerman, O., and Gotthardt, M. (2014) 111Inexendin uptake in the pancreas correlates with the beta cell mass and not with the alpha cell mass, Diabetes.

29. Clardy, S. M., Keliher, E. J., Mohan, J. F., Sebas, M., Benoist, C., Mathis, D., and Weissleder, R. (2014) Fluorescent exendin-4 derivatives for pancreatic beta-cell analysis, Bioconjug Chem 25, 171-177.

30. Brom, M., Woliner-van der Weg, W., Joosten, L., Frielink, C., Bouckenooghe, T., Rijken, P., Andralojc, K., Goke, B. J., de Jong, M., Eizirik, D. L., Behe, M., Lahoutte, T., Oyen, W. J., Tack, C. J., Janssen, M., Boerman, O. C., and Gotthardt, M. (2014) Non-invasive 
quantification of the beta cell mass by SPECT with (1)(1)(1)In-labelled exendin, Diabetologia 57, 950-959.

31. Aguilar-Bryan, L., Nichols, C. G., Wechsler, S. W., Clement, J. P., Boyd, A. E., Gonzalez, G., Herrerasosa, H., Nguy, K., Bryan, J., and Nelson, D. A. (1995) Cloning of the Beta-Cell High-Affinity Sulfonylurea Receptor - a Regulator of Insulin-Secretion, Science 268, 423-426.

32. Conti, L. R., Radeke, C. M., Shyng, S. L., and Vandenberg, C. A. (2001) Transmembrane topology of the sulfonylurea receptor SUR1., J Biol Chem 276, 41270-41278.

33. Bryan, J., Vila-Carriles, W. H., Zhao, G. L., Babenko, A. P., and Aguilar-Bryan, L. (2004) Toward linking structure with function in ATP-sensitive K+ channels, Diabetes 53, S104S112.

34. Mikhailov, M. V., Campbell, J. D., de Wet, H., Shimomura, K., Zadek, B., Collins, R. F., Sansom, M. S. P., Ford, R. C., and Ashcroft, F. M. (2005) 3-D structural and functional characterization of the purified K(ATP) channel complex Kir6.2-SUR1, Embo J 24, 4166-4175. 35. Nichols, C. G. (2006) K-ATP channels as molecular sensors of cellular metabolism, Nature 440, 470-476.

36. Guiot, Y., Stevens, M., Marhfour, I., Stiernet, P., Mikhailov, M., Ashcroft, S. J. H., Rahier, J., Henquin, J. C., and Sempoux, C. (2007) Morphological localisation of sulfonylurea receptor 1 in endocrine cells of human, mouse and rat pancreas, Diabetologia 50, 1889-1899. 37. Gribble, F. M., and Reimann, F. (2003) Sulphonylurea action revisited - the post-cloning era, Diabetologia 46, 875-891.

38. Ladriere, L., Malaisse-Lagae, F., and Malaisse, W. J. (2000) Uptake of tritiated glibenclamide by endocrine and exocrine pancreas, Endocrine 12, 329-332. 
39. Schneider, S., Feilen, P. J., Schreckenberger, M., Schwanstecher, M., Schwanstecher, C., Buchholz, H. G., Thews, O., Oberholzer, K., Korobeynikov, A., Bauman, A., Comagic, S., Piel, M., Schirrmacher, E., Shiue, C. Y., Alavi, A. A., Bartenstein, P., Rosch, F., Weber, M. M., Klein, H. H., and Schirrmacher, R. (2005) In vitro and in vivo evaluation of novel glibenclamide derivatives as imaging agents for the non-invasive assessment of the pancreatic islet cell mass in animals and humans, Exp Clin Endocr Diab 113, 388-395.

40. Schneider, S., Ueberberg, S., Korobeynikov, A., Schechinger, W., Schwanstecher, C., Schwanstecher, M., Klein, H. H., and Schirrmacher, E. (2007) Synthesis and evaluation of a glibenclamide glucose-conjugate: A potential new lead compound for substituted glibenclamide derivatives as islet imaging agents, Regul Peptides 139, 122-127.

41. Schmitz, A., Shiue, C. Y., Feng, Q., Shiue, G. G., Deng, S., Pourdehnad, M. T., Schirrmacher, R., Vatamaniuk, M., Doliba, N., Matschinsky, F., Wolf, B., Rosch, F., Naji, A., and Alavi, A. A. (2004) Synthesis and evaluation of fluorine-18 labeled glyburide analogs as beta-cell imaging agents, Nucl Med Biol 31, 483-491.

42. Mammen, M., Choi, S. K., and Whitesides, G. M. (1998) Polyvalent interactions in biological systems: Implications for design and use of multivalent ligands and inhibitors, Angew Chem Int Edit 37, 2755-2794.

43. Kiessling, L. L., Gestwicki, J. E., and Strong, L. E. (2006) Synthetic multivalent ligands as probes of signal transduction, Angew Chem Int Edit 45, 2348-2368.

44. Martinez-Veracoechea, F. J., and Frenkel, D. (2011) Designing super selectivity in multivalent nano-particle binding, P Natl Acad Sci USA 108, 10963-10968. 
45. Klee, P., Allagnat, F., Pontes, H., Cederroth, M., Charollais, A., Caille, D., Britan, A., Haefliger, J. A., and Meda, P. (2011) Connexins protect mouse pancreatic beta cells against apoptosis, J Clin Invest 121, 4870-4879.

46. Shapiro, A. M. J., Ricordi, C., Hering, B. J., Auchincloss, H., Lindblad, R., Robertson, P., Secchi, A., Brendel, M. D., Berney, T., Brennan, D. C., Cagliero, E., Alejandro, R., Ryan, E. A., DiMercurio, B., Morel, P., Polonsky, K. S., Reems, J. A., Bretzel, R. G., Bertuzzi, F., Froud, T., Kandaswamy, R., Sutherland, D. E. R., Eisenbarth, G., Segal, M., Preiksaitis, J., Korbutt, G. S., Barton, F. B., Viviano, L., Seyfert-Margolis, V., Bluestone, J., and Lakey, J. R. T. (2006) International trial of the edmonton protocol for islet transplantation, New Engl J Med 355, 13181330.

47. Meyer, M., Chudziak, F., Schwanstecher, C., Schwanstecher, M., and Panten, U. (1999) Structural requirements of sulphonylureas and analogues for interaction with sulphonylurea receptor subtypes, British journal of pharmacology 128, 27-34.

48. Tomalia, D. A. (1990) Starburst Dendrimers - Molecular-Level Control of Size, Shape, Surface-Chemistry, Topology, and Flexibility from Atoms to Macroscopic Matter, Abstr Pap Am Chem S 199, 315-ORGN.

49. Kitov, P. I., and Bundle, D. R. (2003) On the nature of the multivalency effect: A thermodynamic model, J Am Chem Soc 125, 16271-16284.

50. Akesson, A., Cardenas, M., Elia, G., Monopoli, M. P., and Dawson, K. A. (2012) The protein corona of dendrimers: PAMAM binds and activates complement proteins in human plasma in a generation dependent manner, Rsc $A d v 2,11245-11248$. 